\title{
THE EFFECTS OF A TEACHER-CHILD PLAY INTERVENTION ON CLASSROOM COMPLIANCE IN YOUNG CHILDREN IN CHILD CARE SETTINGS
}

by

Darren Gabriel Levine

A thesis submitted in conformity with the requirements

for the degree of Doctor of Education

Graduate Department of Human Development and Applied Psychology

Ontario Institute for Studies in Education

University of Toronto

C Copyright by Darren Gabriel Levine 2010 


\title{
THE EFFECTS OF A TEACHER-CHILD PLAY \\ INTERVENTION ON CLASSROOM COMPLIANCE IN \\ YOUNG CHILDREN IN CHILD CARE SETTINGS \\ Doctor of Education 2010 \\ Darren Gabriel Levine \\ Department of Human Development and Applied Psychology \\ University of Toronto
}

\begin{abstract}
The current study evaluated the effect of a teacher conducted play intervention on pre-school aged children's compliance in child care settings. Study participants included 11 children ranging in age from 2 to 5 years old and seven early childhood education teachers within seven classrooms across five child care centres. Teachers were trained to conduct daily 5 minute play sessions consisting of contingent praise, mirroring, and warm responsiveness. A combination $\mathrm{ABAB}$ and multiple baseline design was used to demonstrate the effect of the play intervention. Pre-treatment observations revealed varying degrees of recurring child compliance difficulties. The play intervention was associated with improved rates of compliance for each participant child regardless of differences in age, gender, and level of compliance difficulties. The intervention is discussed with regard to its potential as a pro-active, non-intrusive strategy for improving young children's classroom compliance.
\end{abstract}




\section{ACKNOWLEDGEMENTS}

The completion of this research project signifies the end of a challenging yet rewarding journey, and I would like to thank those who helped make this achievement possible.

I would like to begin by thanking Dr. Joseph Ducharme for his support throughout each stage of this project. Dr. Ducharme's insightful supervision and guidance allowed this project to evolve from an initial proposal to a complete doctoral thesis. I am sincerely appreciative of the numerous hours spent meeting, discussing, and reviewing the many facets of this project. Dr. Ducharme's extensive research on pro-active and non-intrusive methods for addressing children's behavioural difficulties inspired this project, and I am grateful to have been given the opportunity to contribute to this field of study.

I would also like to thank the Social Services Department and the Children's Services Division of The Regional Municipality of Durham for allowing this research project to take place. In particular I would like to thank Dr. Hugh Drouin, Commissioner of Social Services, and Roxanne Lambert, Director of the Children's Services Division for their support of this project.

I wish to thank the children and families who took part in this project and the early childhood educators that not only volunteered to participate, but also skilfully embedded the project's procedures into their already busy daily schedules and routines. Without the participation and commitment of these dedicated professionals, this study could not have taken place.

I would further like to thank my family including my parents and siblings for their support throughout my academic career. Most importantly, I will be forever grateful for the unwavering support of my wife Jennifer. Her constant encouragement and belief that this achievement was within my reach allowed me to remain motivated at times when I was overwhelmed by the magnitude of the task before me. Jen, and our children Maya and Noah have, and continue to be, a constant source of inspiration and the reason why I set forth and remained committed to this journey. It is to them that I dedicate this thesis. 


\section{TABLE OF CONTENTS}

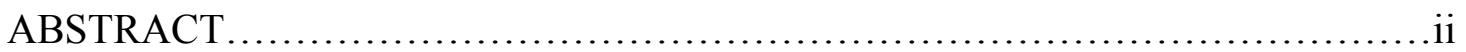

ACKNOWLEDGEMENTS .....................................................ii

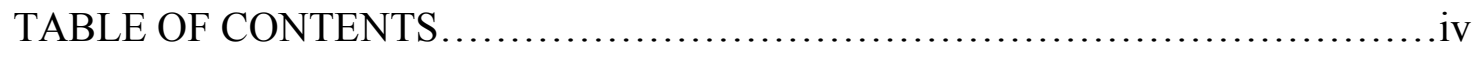

CHAPTER ONE - INTRODUCTION.............................................

Young Children's Challenging Behaviour................................

Parent-Child Interaction...............................................

Child Care Settings and Teacher-Child Interaction.......................... 4

Reactive Classroom Management........................................5

Positive Teacher-Child Interactions as an Antecedent

Classroom Management Strategy.........................................

Stimulus Control Variables......................................... 7

Ecological Variables........................................... 9

Play and Child Compliance............................................ 10

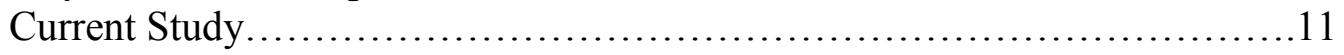

CHAPTER TWO - METHODS............................................... 12

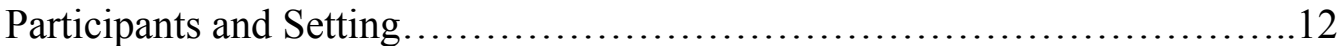

Recruitment.......................................................... 12

Dependent Variable - Child Compliance.....................................13

Independent Variable - Play Sessions................................... 14

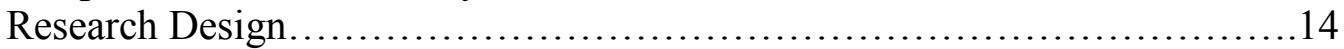

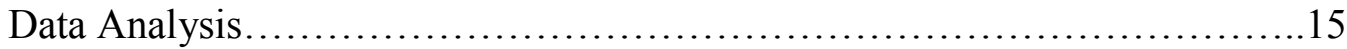

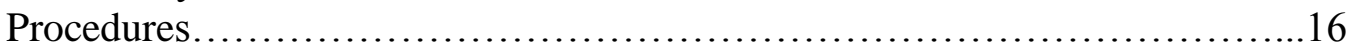

Request Selection..........................................16

Request Delivery Procedure Review..............................17

Request Delivery................................................ 17

Baseline Phase......................................................18

Play Session Procedure Review........................................19

Play Phase One................................................. 20

Withdrawal Phase ..............................................20

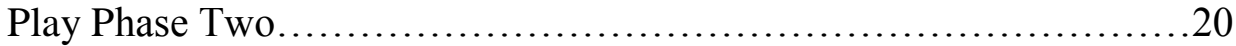

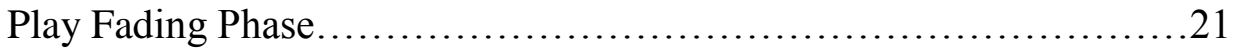

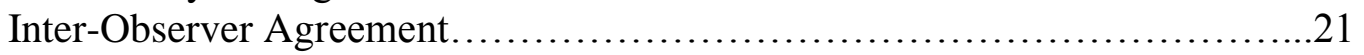

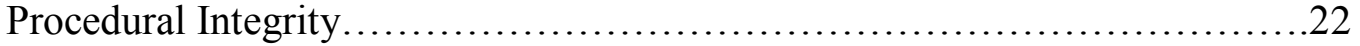

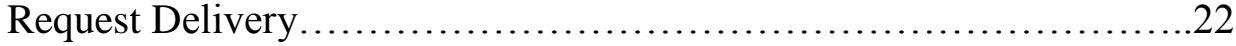

Teacher-Child Play Sessions......................................23

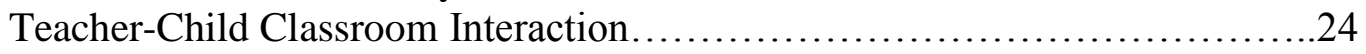


CHAPTER THREE - RESULTS ...........................................25

Child Compliance.................................................... 25

Baseline Phase (Screening)......................................25

Teacher Compliance Probability Ratings...........................29

Baseline Compliance for Participant Children........................31

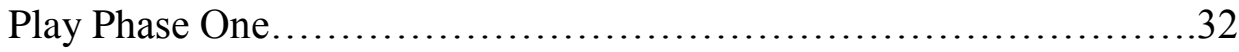

Withdrawal Phase ................................................33

Play Phase Two................................................ 33

Play Fading Phase.............................................. 33

Teacher-Child Classroom Interaction................................... 36

CHAPTER FOUR - DISCUSSION $\ldots \ldots \ldots \ldots \ldots \ldots \ldots \ldots \ldots \ldots \ldots \ldots \ldots \ldots \ldots \ldots \ldots \ldots . . .41$

Improved Child Compliance............................................41

Ecological Variables..............................................43

Stimulus Control.............................................43

Combination of Stimulus Control and Ecological Variables.............44

Maintenance of Child Compliance After Withdrawal of Play............44

Limitations and Consideration for Future Research........................47

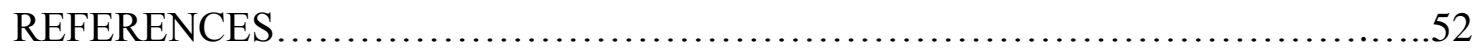

APPENDICES .............................................................66

Appendix A - Informed Consent Packages................................66

Appendix B - Compliance Probability Checklist.............................78

Appendix C - Child Compliance Data Collection Form......................80

Appendix D - Researcher Child Compliance and Procedural Integrity

Data Collection Form........................................81 


\section{CHAPTER ONE: INTRODUCTION}

\section{Young Children's Challenging Behaviour}

Challenging behaviour can be a serious concern in young children (Anderson, 1994;

Egger \& Angold, 2006; Sawyer et al., 2000). As many as $14 \%$ of children between the ages of eighteen months and three years exhibit severe levels of externalizing problems such as aggression and defiance (Bayer, Hiscock, Ukoumunne, Price, \& Wake, 2008) and approximately half of all clinical referrals for children involve conduct difficulties (Essau, 2003).

Challenging behaviour is exhibited by many children as a typical part of development, and many conduct problems improve during the pre-school years as children acquire language, social, and problem-solving skills (Campbell, 1995). Approximately 10\% of young children however, continue to experience behavioural difficulties into their school age years (Kupershmidt, 2000) with child non-compliance being one of the most prevalent and frequently reported problems (Feinfeld \& Baker, 2004).

Severe behavioural difficulties are of particular concern in young children as these problems have the potential to worsen and continue into adolescence and adulthood (Barkley et al., 2002; Bosquet \& Egeland, 2006; Campbell, 1995). For example, young children's severe non-compliance has been identified as a pre-cursor to the development of later conduct problems (McMahon \& Forehand, 2003) and increased risk of later socialization, school, and vocational difficulties (Campbell, 1995; Fox, Dunlap, \& Powel, 2002).

Teachers of young children indicate that challenging behaviour is one of their biggest concerns and a significant source of stress (Alkon, Ramler, \& MacLennon, 2003; Joseph \& Strain, 2003; Stoughton, 2007). Within day care settings, as many as $20 \%$ of children between the ages of two and five years have been found to exhibit problem responses such as destruction, temper tantrums, and noncompliance (Crowther, Bond, \& Rolf, 1981). These types of severe 
challenging behaviours jeopardize young children's participation in early learning programs. In a survey of 60 child care teachers, Buck and Ambrosino (2004) found that nearly half of the teachers surveyed reported that a child had been removed from their care due to behavior difficulties. In the same study, $85 \%$ of the participant teachers requested information on methods to address children's difficult behaviour, highlighting the need for classroom-based interventions that can be easily implemented by child care teachers (Buck \& Ambrosino, 2004).

The development of a child's behavioural repertoire is influenced by both child characteristics and environmental variables. These internal and external variables can serve as either risk factors increasing the likelihood that children will develop adjustment problems later in life, or protective factors decreasing the probability of later adjustment problems (Ladd \& Burgess, 2001). Some of the most common risk factors associated with externalizing behaviour problems include characteristics of the home and school environments such as teacher's poor classroom management skills, a controlling parenting style, harsh discipline practices, and conflictual parent-child interactions (Bosquet \& Egeland, 2006; Kellam, Ling, Merisca, Brown, \& Ialongo, 1998; McCarty, Zimmerman, Digiuseppe, \& Christakis, 2005; Patterson, 1982; Vando, Rhule-Louie, McMahon, \& Spieker, 2008; Webster-Stratton \& Hammond, 1998; West, Denton, \& Reaney, 2001). Exposure to risk factors however, does not always engender development of child behaviour problems. Child variables such as language, cognitive, and social skills, and characteristics within a child's environment such as warm, responsive parenting, stimulating high quality child care, and positive relationships with others, can serve as protective factors mediating the effects of exposure to psycho-social stressors on children's adjustment (Brody \& Flor, 1998; Fox, Dunlap, \& Powell, 2002; Goodman, Aber, Berlin, \& Brooks-Gunn, 1998; Hoge, Andrews, \& Leschied, 1996; Katz \& Gottman, 1997; Linver, Brooks- 
Gunn, \& Kohen, 2002; Marcus \& Betzer, 1996; Peisner-Feinberg et al., 2001; Peisner-Feinberg \& Burchinal, 1997; Vandell, 2004; Webster-Stratton, Reid, \& Stoolmiller, 2008).

\section{Parent-Child Interaction}

Through repeated interactions with their parents or parent figures during the early years of development, children come to learn how their caregivers will interact with them and respond to their needs. Early parent-child interactions work to shape children's beliefs and expectations about the availability and sensitivity of their parents during times of need, with parent responsiveness being a key factor influencing the nature of parent-child relationships (Bowlby, 1980; Bretherton, 1992; Green, Stanley, \& Peters, 2007; Kobak, 1999).

As parents demonstrate warm, sensitive, and consistent responsiveness towards their infants during the early years, infants learn to trust that their parents will be present to offer comfort in times of stress. Over time, this trust allows children to view and utilize their parents as a secure base from which to explore and interact with their surroundings, gradually moving from the need for close proximity to the parent to more autonomous exploration of their environment (Bowlby, 1980; Bretherton, 1992; Green et al., 2007; Kobak, 1999). The transition from dependence to independent exploration increases opportunities for children to interact with others, thereby encouraging development of social skills and peer relations and rendering externalizing and internalizing behavioural difficulties less likely (Humber \& Moss, 2005; Shaw, Keenan, Vondra, Delliquadri, \& Giovanelli, 1997).

In addition to fostering children's pro-social skills, warm and responsive parenting promotes and reinforces positive patterns of adult-child interaction that can substantially affect both parent and child behaviour. As parents provide regular acknowledgment of the child and positive feedback for desired responses, children typically respond by seeking further parental 
commendation through demonstration of more diverse forms of pro-social behaviour. This inturn elicits further parental reinforcement (Patterson, 1982; Wahler \& Dumas, 1984) and a generally cooperative parent-child relationship. On the other hand, harsh and power assertive parenting contributes to the development of uncooperative and coercive behaviour. As parents try to compel children to comply with their demands and children push back with defiant efforts to coerce parents to withdraw their ultimatums, negative parent and child behaviours may be inadvertently reinforced. If either the parent or the child is successful in their confrontational attempts to alter the other's responses, each will be more likely to make use of such coercive patterns of interaction in the future (Patterson, 1982; Wahler \& Dumas, 1984). Thus child conduct problems can become entrenched through harsh parenting practices.

\section{Child Care Settings and Teacher-Child Interactions}

For many children, experience with non-parental caregivers begins within early learning and childcare settings. In 1995, 40\% of Canada's 2.3 million children aged five and under spent an average of 27 hours each week in non-parental childcare, with $23 \%$ of these children enrolled in a child care centre (McCain \& Mustard, 1999; Statistics Canada, 2005). By the year 2001, the number of children in non-parental child care had risen to more than one-half of children in Canada between the ages of six months and five years old, with $25 \%$ of these children enrolled in centre-based care (Statistics Canada, 2005).

In these non-parental child-care settings, children's interactions with teachers and other influential caregivers play an important role in their development and behavior, similar to that of interactions with parents (O’Connor \& McCartney, 2007; Stacks, 2007). A supportive relationship with at least one teacher has been noted as one of the most important protective 
factors influencing children's success in school (Pianta \& Walsh, 1998; Werner, 1999). Positive interactions between young children and their teachers promote child pro-social development and academic achievement. Such exchanges can help children acquire a wide range of skills, including compliance, assertiveness, and proficiency in adult and peer relations (Pianta, 1999). Teacher positive affect towards children and avoidance of harsh or controlling commands and consequences have been found to prevent conduct problems (Burchinal, Roberts, Hooper, \& Zeisel, 2000), promote higher rates of compliance to teacher requests (Corrigan, 2006; Wachs, Gurkas, \& Kontos, 2004), and increase social skills and academic achievement (Cassibba, Van Ijzendoorn, \& D’Odorico, 2000; De Kruif, McWilliam, Ridley, \& Wakely, 2000; Palermo, Hanish, Martin, Fabes, \& Reiser, 2007; Pianta, Steinberg, and Rollins, 1995).

\section{Reactive Classroom Management}

As with parent-child relations, teachers and children may also become entrenched in problematic patterns of interaction. Such negative teacher-child exchanges have been associated with children's aggressive and oppositional behaviour, social withdrawal, diminished classroom participation and cooperation, and decreased liking of school (Arnold et al., 1999; Arnold, Griffith, Ortiz, \& Stowe, 1998; Birch \& Ladd, 1997; Campbell \& Ewing, 1990; Carr, Taylor, \& Robinson, 1991; Howes, Hamilton, \& Matheson, 1994; Ladd \& Burgess, 2001).

In many classroom settings, teacher responses to child problem behavior tend to be reactive, rather than pro-active (Conroy \& Brown, 2004). Children with behavioural difficulties have been found to experience more negative interactions with their teachers and receive less positive teacher feedback and support (Arnold et al., 1998; Arnold et al., 1999; Campbell \& Ewing, 1990; Carr et al., 1991). Some of the most frequently employed strategies for classroom 
management involve teacher statements of disapproval, verbal reprimands, and child exclusion (Bacon, 1990; Turner \& Watson, 1999). Such reactive techniques are intended to inhibit the problem responses so that they stop immediately and are less likely to occur in the future. Although these techniques may result in the short-term cessation of problem behaviour, they have the potential to exacerbate rather than improve children's behaviour difficulties (Mayer, 2001) and impede positive teacher-child interactions (Austin \& Agar, 2005). As well, such consequences do not teach children any new, more socially appropriate strategies for dealing with the difficult circumstances that often lead to problem behaviours (Bear, 1998; Ducharme, 1999).

Related to this concern is the fact that children's behaviour problems often stem from excessive exposure to stressors such as poverty (Bolger, Patterson, Thompson, \& Kupersmidt, 1995), family violence (Pianta \& Egeland, 1994), and parenting difficulties (Chamberlain \& Patterson, 1995). Ducharme and Harris (2005) assert that severe behavioural difficulties can often be viewed as a child's only means of adapting to adverse environments (Lewis, 1997, as cited in Ducharme \& Harris, 2005). As such, interventions that focus solely on the suppression of problem behaviours without teaching any new alternative skills may eliminate the only coping strategies available to these children (Ducharme \& Harris, 2005).

For these reasons, researchers have begun to examine positive and reinforcement-based approaches for building a repertoire of pro-social behaviour in children with conduct difficulties, commonly involving the delivery of rewarding consequences to increase the probability of desired child skills (e.g., Austin \& Soeda, 2008; Boelter et al., 2007; Bullock \& Normand, 2006; Wilder, Harris, Reagan, \& Rasey, 2007; Wilder, Saulnier, Beavers, \& Zonneveld, 2008). However, as noted by Ducharme and Harris (2005), reinforcement-based procedures alone are 
often unsuccessful in treatment for children exhibiting severe behaviour difficulties (e.g, . Barkley, 2000; Forehand, 1986; Rosen, O’Leary, Joyce, Conway, \& Pfiffner, 1984). For this reason most formalized treatments include concurrent use of some form of reductive consequence such as timeout, to increase the probability of meaningful treatment effects (e.g., Eyberg, Boggs, \& Algina, 1997; Webster-Stratton, 2001). Thus, in addition to reinforcement, other treatment components must be considered to promote optimal child outcomes (Dunlap, Kern-Dunlap, Clarke, \& Robbins, 1991).

\section{Positive Teacher-Child Interaction As An Antecedent Classroom Management Strategy}

One such consideration relates to the immediate, observable context in which child behaviour occurs (Kern, Choutka, \& Sokol, 2002). In particular, through examination of behavioural antecedents (events that occur immediately before a behaviour), clinicians can determine environmental conditions that may be closely related to the problem response. As part of an intervention approach, they can withdraw such triggers for problem behaviour and present to the child those conditions associated with more pro-social alternative responses, especially at times when problem behaviours are most likely to occur.

\section{Stimulus Control Variables}

Because antecedent approaches can reduce the probability of problem responses, they may also decrease the need for punitive consequences (Luiselli, 1998). Many antecedent interventions involve the manipulation of discriminative stimuli (events that serve as signals for a particular behaviour to occur). Behaviours occurring in response to a discriminative stimulus that are subsequently reinforced are more likely to occur in the presence of that stimulus in the future (Kern et al., 2002). For example, a child may respond with challenging behaviour to a 
demanding task that he finds aversive. If that problem response leads to escape from the task's demands, the child will likely continue to exhibit challenging behaviour following each presentation of the task. When a behavior continually occurs in the presence of such conditions, and does not occur in the absence of those same conditions, the behavior is said to be under stimulus control of those conditions (Martin \& Pear, 1996; Rodewald, 1979). Identification of such conditions for clinical purposes allows the treatment provider to re-arrange the environment to increase the presence of stimuli and situations that have stimulus control over pro-social child behaviours, and reduce those that have stimulus control over problem behaviours (Ducharme, 1999).

Through the regular presentation of stimuli that control pro-social behaviours, the improved behavioural repertoire of the child may produce a range of positive adult responses (e.g., praise, pleasant conversation). These pleasant interactions may then serve as discriminative stimuli for an array of desired child behaviours that continue a cycle of warm and responsive interactions (Kern et al., 2002). For example, providing pleasant conversation, prompts, and individualized assistance to a child who typically tries to escape an aversive task will alter antecedent conditions in a manner that may lead to prosocial rather than disruptive behaviour (i.e., by arranging circumstances that the child is less likely to want to escape). These new prosocial child responses may then promote positive responses from the teacher, thus maintaining the newly created cycle of positive interaction and increasing the future likelihood of child prosocial responses. 


\section{Ecological Variables}

In addition to stimulus control variables, researchers have documented another class of antecedent factors that play a role in the onset of children's behavioral difficulties. Ecological variables (Ducharme, 1999) are more difficult to assess or observe than stimulus control variables because they often do not occur in temporal or physical proximity to the behaviours of concern. They may include physiological states such as hunger or fatigue, physical discomfort such as a headache or allergies, and emotional discomfort such as the distress caused by negative interactions with family members. Similar to stimulus control variables, ecological variables do not directly cause specific problem behaviors, but may serve to increase their probability (Horner, Vaughn, Day, \& Ard, 1996).

An operant learning concept closely related to ecological variables is "establishing operations", those antecedent variables that momentarily alter the reinforcing effectiveness of behavioural consequences (Michael, 2000). These variables can affect the probability of a behaviour by enhancing the perceived value of a certain outcome to a child, thereby increasing motivation to exhibit responses that will access that outcome (Michael, 2000). For example, under typical conditions, a child may respond without problem behaviour to an academic demand placed on her by her teacher. However, when the youngster is highly fatigued, hungry, or emotionally distraught, the task may be perceived as aversive and lead to problem behaviour focused on securing escape from the task demands. Under the extenuating circumstances of the ecological variables, escape from the task is perceived to be more reinforcing than might otherwise be the case, and the child is more motivated to display those behaviors that have come to be associated with escape from task demands (Kern et al., 2002; Smith \& Iwata, 1997). 
Some forms of adult-child interactions may be conceptualized as an ecological variable because they affect child behaviour in the manner described above. For example, negative interactions with an adult at home may set the stage for task avoidance, noncompliance and other problem behaviour at school, as everyday academic and social challenges become much more difficult to manage when the child is in emotional distress. In contrast, warm and responsive adult-child interactions may increase the probability of child cooperation with an adult by increasing the perceived reinforcing value of positive adult attention. When interactions with adults are deemed valuable, children may be more likely to cooperate with adult directives in order to continue obtaining the highly desired outcome of positive adult attention. This may be particularly true for children with behaviour difficulties, whose history of interactions with adults may consist mainly of negative adult reactions to child misbehaviour.

\section{Play and Child Compliance}

In recent years, parent-child and teacher-child rapport-based play has been demonstrated to be an effective means by which to enhance children's compliance in both home and school environments (e.g., Corrigan, 2006; Ducharme \& Rushford, 2001). For Example, Ducharme and Rushford (2001) demonstrated that short adult-child play sessions can significantly improve child compliance. In this study, a 45-year-old father and his 10-year-old son were struggling in their interactions after the father acquired a severe brain injury. Their strained relationship was characterized by child avoidance and non-compliance. Although the child rarely complied with directives from his father during baseline, his compliance climbed to high levels following the introduction of brief parent-child play sessions. During a reversal phase when play sessions were not conducted, compliance levels decreased but recovered again following re-introduction of the play periods. 
Building on these findings, Corrigan (2006) demonstrated that improvements in children's classroom compliance could be brought about through the introduction of warm and responsive play sessions between a teacher and her students. Corrigan (2006) implemented the antecedent play intervention across two grade three classrooms with 10 children exhibiting severe noncompliant behaviour. Following baseline measurement of child compliance, teachers were trained to engage in 10 minutes of play daily with each participant student. Following the introduction of these play sessions, mean child compliance increased from baseline rates of $44 \%$ in the first classroom and $38 \%$ in the second classroom, to $73 \%$ in both classrooms. Subsequent withdrawal and play session phases demonstrated that child compliance was high when play was part of the teacher's daily repertoire and lower when the teacher did not use such a strategy (Corrigan, 2006).

\section{Current Study}

With increasing numbers of young children taking part in non-parental child care during their early years of development, there is a need for more research examining positive-based interventions that can be easily implemented by childcare teachers in early learning classrooms. Corrigan (2006) demonstrated the effectiveness of antecedent teacher-child play sessions as a stand-alone intervention for school-aged children's compliance in the classroom. The current study will expand on the findings of this study with the objective of evaluating the effect of short teacher-child play sessions on pre-school aged children's compliance in child care settings. The primary research questions are:

1. Will short teacher-child play sessions result in improvements in child compliance to teacher requests that follow the sessions?

2. Will these gains maintain when the antecedent play sessions are terminated? 


\section{CHAPTER TWO: METHODS}

\section{Participants and Setting}

Following the collection of baseline screening compliance data for 71 children (see baseline phase procedures), study participants included 11 children ranging in age from 2 to 5 years old and seven child care teachers. The age and gender of participating children are outlined in Table 1. This study was conducted within seven classrooms across five child care centres over an 11-month period. Participating child care centres were located in the Region of Durham including the cities of Pickering, Ajax, Whitby, Bowmanville, and Oshawa.

\section{Table 1}

Age and Gender of Participating Children

\begin{tabular}{llllll}
\hline Participant & Gender & Age & Participant & Gender & Age \\
\hline Child 1 & Female & 3 yrs & Child 7 & Female & 2 yrs \\
Child 2 & Male & 3 yrs & Child 8 & Male & 2 yrs \\
Child 3 & Male & 3 yrs & Child 9 & Female & 4 yrs \\
Child 4 & Male & 4 yrs & Child 10 & Male & 4 yrs \\
Child 5 & Male & 3 yrs & Child 11 & Female & 4 yrs \\
Child 6 & Male & 5 yrs & & &
\end{tabular}




\section{Recruitment}

A multi-step recruitment process was utilized for this study. Supervisors of child care centres operated by the Regional Municipality of Durham were informed about this research project and asked to contact the researcher if they were interested in having the study take place at their centre. Interested centre supervisors then met with the researcher to discuss the study in greater detail. Once supervisors agreed to have the study take place in their centre, teachers of the pre-school age classrooms were informed of the study, and asked to contact the researcher if they wished to participate. Interested teachers then met with the researcher to discuss the study in greater detail.

Once consent was obtained from teachers, informed consent letters were sent to the parents of all of the children in the classrooms. Parents interested in having their children participate in this study were provided with an opportunity to meet with the researcher to discuss the study in greater detail and, once consent was obtained, baseline data collection commenced. See appendix A for copies of the informed consent packages.

\section{Dependent Variable - Child Compliance}

The dependent variable was child compliance to teacher requests, defined as the initiation of the appropriate motor response to a teacher's request within 10 seconds of the request, and completion of the motor response within 40 seconds (Ducharme, 1996). Child responses to teacher requests were scored as either compliant or non-compliant based on the above definition. The percentage of teacher requests to which a child complied was measured repeatedly for each child over all phases of the study. 


\section{Independent Variable - Play Sessions}

The independent variable involved the initiation of teacher-child play sessions, defined as the classroom teacher engaged in a daily 5-minute non-directive one-to-one play activity with participant children. As in Corrigan (2006), the teachers were asked to demonstrate the following behaviours during these play sessions: a) contingent praise, defined as the teacher providing enthusiastic positive statements to the child following pro-social responses and behaviours by the child; b) warm responsiveness, defined as the teacher being warm, sensitive, playful, and empathetic toward the child during the interaction, and acknowledging and demonstrating interest in child comments and responses; c) mirroring, defined as the teacher providing a verbal description of the child's non-verbal behaviour or paraphrasing the child's verbal behaviour; $d$ ) creating success opportunities, defined as the teacher arranging conditions to ensure that the child experiences success in the activity; e) acquiescence, defined as the teacher accepting the child's lead and recommendations during the interaction; f) non-directive interacting, defined as the teacher not delivering requests and instructions that require compliance, but instead suggesting possible play directions. All teacher-child play sessions took place in the child's classroom during free play periods as part of the daily routine. The play sessions occurred at approximately the same time of day each day over the course of the study.

\section{Research Design}

A combination $\mathrm{ABAB}$ and multiple baseline design was used in this study (Barlow \& Hersen, 1984; Ducharme \& Worling, 1994). Within each classroom, the first phase (A phase) was the baseline phase during which no intervention occurred. This phase was followed by the play phase (B phase) during which the play intervention was conducted. The play intervention was then withdrawn (second A phase) to determine whether improvements in child compliance 
associated with the play intervention would decline in the absence of the intervention. When a decrease in child compliance was observed, a second play phase (B phase), followed by a play fading phase, were utilized to determine if treatment effects could be re-established and maintained once the intervention was reintroduced.

A multiple baseline design (Barlow \& Hersen, 1984) was used to add further experimental rigor to the design and more clearly demonstrate the effect of the teacher-child play intervention on child compliance. In conjunction with the $\mathrm{ABAB}$ design, baseline phases were varied for each participant child to demonstrate that changes in children's compliance occurred only following the introduction of the intervention, regardless of the duration of baseline measurement. All baselines were initiated concurrently in multiple baseline fashion within child care centres but each centre was run sequentially for practical reasons (i.e., resource limitations).

\section{Data Analysis}

Visual analysis was the primary strategy used for examining trends in the data and involved an examination of level and pattern of the data from pre-treatment to treatment. Visual analysis of data shown in graphical form can indicate clinically significant effects (Barlow, Hayes, \& Nelson, 1986; Ducharme, Atkinson, \& Poulton, 2000). In the current study, an examination of the proportion of sessions from pre-treatment to treatment in which compliance was perfect (i.e., 100\%), as well as the proportion of sessions at 50\% compliance or less was conducted for each participant child. 


\section{Procedures}

\section{Request Selection}

Prior to the start of the baseline phase, teachers were asked to complete a modified, classroom-based version of the Compliance Probability Checklist (Ducharme \& DiAdamo, 2005). Originally designed to evaluate parent perception of child compliance to household requests (Ducharme, Atkinson, \& Poulton, 2000; Ducharme, Davidson, \& Rushford, 2002;

Ducharme, Popynick, Pontes, \& Steele, 1996;) the compliance probability checklist was utilized in the current study to determine teacher perception of each child's compliance to requests commonly administered by teachers to children in their classrooms.

Teachers were asked to complete one compliance probability checklist for each participant child in their classrooms. The teachers were asked to rate each request on the checklist according to their best estimate of the likelihood of child compliance. Compliance ratings included: Level 1 "almost always complies" (76 to 100\% of the time); Level 2 "usually complies" (51 to 75\%); Level 3 "occasionally complies" (26 to 50\%) and Level 4 "rarely complies" (0 to 25\%). The checklist sampled a range of classroom requests that were appropriate for young children (see Appendix B). For each request selected, teachers further noted whether they typically administered the request to individual children or to the entire class of students. This information was included to ensure that requests were administered in the same manner (e.g., to individual children or to the group of children) through the study phases.

For each child, five requests identified by teachers as lower probability (i.e., rated as "usually", "occasionally", or "rarely") were selected from the completed checklists and placed on a child compliance data collection form for use during request delivery phases of the study 
(see Appendix C). If all requests on the checklist were identified as high probability of compliance, five requests sampling the various domains represented on the checklist were selected. Thus, an individualized set of requests was used for each child.

\section{Request Delivery Procedure Review}

Prior to the start of baseline data collection, participant teachers met with the researcher for review of request delivery procedures to reduce the likelihood of procedural drift. These meetings ranged in duration from 30 to 45 minutes.

As in the Corrigan (2006) study, request delivery procedures involved teachers: a) maintaining close proximity to the child; b) obtaining the child's attention prior to administering each request; c) delivering single component requests as listed on the data sheet; d) phrasing requests as an imperative rather than as a question; e) allowing adequate time to respond before a request was repeated. Teachers were also asked to ensure that instructions identified on the data sheet as group requests were consistently provided to the entire class of children, and that those instructions identified as individual child requests were administered directly to each participant child. This additional procedure was included in order to ensure that the requests delivered by participating teachers reflected the range and type of requests commonly administered to young children in child care settings, and to avoid teachers having to alter the manner in which requests were currently being delivered in their classrooms.

\section{Request Delivery}

Within each classroom, teachers were paired with participant children and were asked to deliver the list of predetermined requests to those children over the course of the study. Throughout all phases of the study, teachers administered the requests to the children once each 
day in random order and at natural times of the day. The occurrence of compliance or noncompliance was recorded by teachers immediately following the administration of each request. Throughout all phases of this study, the teacher provided the same set of instructions to the same children at approximately the same time of day (morning or afternoon) each day. These procedures were included to ensure that any changes in compliance rates across phases were not due to uncontrolled procedural variables.

\section{Baseline Phase}

Baseline compliance data were collected for all children for whom informed consent was obtained. In total, 71 children with 17 child care teachers across 10 classrooms in six child care centres took part in baseline phases to screen for study participation. See table 2 for summary information on the children that took part in baseline data collection. Baseline child compliance data were collected for each child until a pattern of compliance could be established. Those children demonstrating average baseline compliance of $50 \%$ or lower, or demonstrating fluctuating patterns of compliance, were selected to participate in the play phases of this study. All baseline data collected for those children selected as participants was used as the formal baseline against which play phase data could be compared. 


\section{Table 2}

Children Screened for Study Participation

\begin{tabular}{lcll}
\hline Age & No. Children & Male & Female \\
\hline 2 years & 10 & 4 & 6 \\
3 years & 29 & 19 & 10 \\
4 years & 23 & 15 & 8 \\
5 years & 8 & 4 & 4 \\
6 years & 1 & 0 & 1 \\
\hline Total & 71 & 42 & 29
\end{tabular}

\section{Play Session Procedure Review}

After the baseline phase, but before the first play phase, participant teachers met with the researcher to review play session procedures to be used with the 11 children selected for study participation. These meetings were 30 minutes in duration. In addition to training in all procedures described in the "independent variable" section, participant teachers were asked not to respond to any problematic behaviours demonstrated by the children during the play sessions unless the behaviour posed a safety risk to the child, the teacher, or any other children or adults in the classroom. 
Teachers were also instructed to obtain child assent before beginning each play session. If a child declined to participate in the play session, teachers were told to suspend the play session for that day and proceed with the usual classroom schedule. As well, if a child left a play session before the scheduled end of the session, or indicated that he or she no longer wanted to participate in play with the teacher, the teachers were instructed to immediately end the play session for that day and proceed with the usual classroom routine (over the course of this study, no children failed to provide assent or withdrew from a play session before the end of the scheduled play period).

\section{Play Phase One}

Teachers spent five minutes each day engaged in the non-directive, one-to-one play session with participant children. Immediately following the daily play sessions, the teachers administered the same requests used in the baseline phase to participant children in as natural a manner as possible. Request delivery and child compliance data collection procedures were exactly as in baseline.

\section{Withdrawal Phase}

During the withdrawal phase, teachers did not conduct play sessions. Request delivery and child compliance data collection were exactly as in baseline and play phase one.

\section{Play Phase Two}

With the re-initiation of play sessions, this phase was conducted exactly as in play phase one. Request delivery and child compliance data collection were exactly as in baseline, play phase one, and withdrawal phases. 


\section{Play Fading Phase}

The purpose of this final phase was to systematically fade the play sessions to increase the probability that the compliance gains would maintain after study completion. Teachers were asked to implement the 5-minute play sessions each day, but to gradually reduce the duration of the sessions. Play sessions were systematically faded from 5 minutes at the start of this phase, to two and a half minutes mid-way through this phase, to complete cessation of the play sessions by the end of this phase. Request delivery and child compliance data collection were exactly as in baseline, play phase one, withdrawal, and play phase two.

\section{Inter-Observer Agreement}

As a measure of inter-observer agreement on observational data, both the participating teachers and the researcher simultaneously collected child compliance data. Throughout each study phase, the researcher attended randomly selected compliance sessions. During these sessions, the teacher administered the identified requests to the children and both the teacher and the researcher independently identified the occurrence of child compliance or non-compliance following each request.

Agreement was defined as both observers independently agreeing on the occurrence or non-occurrence of a compliant response by the child after request delivery by the teacher. The researcher observed an overall mean of $50 \%$ of the requests administered by the participant teachers over the course of this study (range of $30 \%$ to $76 \%$ across teachers). Periodic reviews of the operational definition of compliance and non-compliance were conducted by the researcher with participant teachers over the course of the study to ensure consistency in data collection 
procedures. Agreement was obtained on $98 \%$ (range of $92 \%-100 \%$ across teachers) of the observed requests.

\section{Procedural Integrity}

As a measure of the extent to which teachers adhered to study procedures, data were collected on teacher behaviour during request delivery and play sessions. Within each phase of this study, the researcher attended randomly selected teacher-child play and compliance sessions. During the compliance sessions, the researcher observed the manner in which teachers delivered requests to the children and recorded the occurrence or non-occurrence of expected request delivery procedures. Similarly, during play sessions, the researcher observed the five minute teacher-child play sessions and identified the occurrence or non-occurrence of expected teacher play behaviors.

\section{Request Delivery}

Procedural checks were conducted for $46 \%$ of the requests administered by the participating teachers over the course of the study (range of $32 \%$ to $74 \%$ across teachers). Following each observed request, the researcher indicated next to each request listed on children's compliance data sheets (see Appendix D) whether that request was administered correctly (i.e., the researcher placed a "check" next to each request delivered correctly). Data sheets for each child were developed in advance of observation sessions so as to reflect each child's unique set of requests. Correct request delivery was defined as the teacher correctly administering each request as either a group or individual request (as identified on each child's data sheet), and in the manner outlined in the aforementioned "request delivery procedure review" section. A request was deemed incorrect if one or more of the expected request delivery 
procedures were absent. Percent adherence was determined by dividing the number of requests delivered correctly by the total number of requests delivered. Expected request delivery procedures were present in $94 \%$ of requests checked. Percent adherence ranged from $85 \%-100 \%$ across participant teachers.

\section{Teacher-Child Play Sessions}

Procedural checks were conducted for $41 \%$ of the teacher-child play sessions (range of $22 \%$ to $62 \%$ across teachers). During each observed 5-minute play session, the researcher indicated on each child's data sheet (see Appendix D) if the play session took place, whether the child provided assent to participate, if it was conducted for the expected duration, and if it was comprised of the expected play session procedures outlined in the "independent variable" section. The intent of the play session procedures was to create a warm, successful, childdirected playful interaction between a child and teacher without any expectation of child compliance (i.e., teacher joining child's play, offering praise for child pro-social behavior, and mirroring child's play behaviour and verbalizations instead of controlling the activity and providing directives). As such, it was not expected that every play session procedure would be demonstrated by each teacher during every play session, but rather that teachers would embed as many of the play session procedures as possible into each play session. A play session was deemed correct if it consisted of a minimum of child-directed play, teacher praise for child prosocial behavior, and the absence of teacher directives. Percent adherence was determined by dividing the number of play sessions conducted correctly by the total number of play sessions conducted. An average of $97 \%$ of the observed play sessions were conducted correctly, with percent adherence ranging from $86 \%-100 \%$ across participant teachers. 


\section{Teacher-Child Classroom Interaction}

During randomly selected observation sessions within each phase of this study, the researcher gathered exploratory data on the number of positive teacher-child classroom interactions that occurred naturally outside of the scheduled play sessions. Positive interactions were defined as teacher demonstrations of warm responsiveness, praise, sensitivity, playfulness, positive attention or interest towards the child, whether initiated by the child or the teacher. This procedure was included to explore whether, as a result of participating in the teacher-child play sessions, increases in positive interactions between the children and teachers might begin to occur naturally in the classroom. As teachers were not informed of this procedure until after the completion of the study (so as not to influence teacher behaviour during each phase), these data were collected by the researcher during already scheduled compliance observation sessions throughout each study phase. During observation sessions, the researcher made note of the number of positive interactions that took place (i.e., a tally count indicating the number of observed positive interactions). A "check" was placed on the data sheet (see appendix D) each time any of the abovementioned types of positive interactions were observed during an observation period. These observation periods averaged 45 minutes in duration, ranging between 20 and 60 minutes, based on the length of time it took for teachers to administer identified requests to participant children. As such, these interactions were examined as a proportion of the observation period in which they were collected. This was done by dividing the number of positive interactions that occurred during each observation period by the duration (number of minutes) of the observation period in which they were recorded. 


\section{CHAPTER THREE: RESULTS}

\section{Child Compliance}

\section{Baseline Phase (Screening)}

Baseline compliance data were collected for 68 of the 71 children screened for participation in this study. Three children withdrew from the study due to circumstances requiring them to leave the child care centre in which the study was taking place, and one participating teacher withdrew from the study prior to the completion of baseline data collection due to competing classroom responsibilities. Over the course of the baseline phase, the 68 children demonstrated a combined average rate of compliance of $84 \%$, ranging from $75 \%$ to $90 \%$ across the six child care centres, with $78 \%$ of the children exhibiting average rates of compliance greater than $76 \%$. Only five children demonstrated average rates of compliance below $50 \%$. As a result of these findings, 11 of the 68 children met the criteria to proceed to the play phases of the study (i.e., demonstrated average baseline compliance of $50 \%$ or lower, or a fluctuating pattern of compliance). See tables 3 through 9 for baseline rates of compliance.

\section{Table 3}

Summary of Baseline Child Compliance

\begin{tabular}{lcc}
\hline Average Compliance & Number of Participants & Percent of Total Participants \\
\hline $76 \%-100 \%$ & 53 & $78 \%$ \\
$51 \%-75 \%$ & 10 & $15 \%$ \\
$26 \%-50 \%$ & 4 & $6 \%$ \\
$0 \%-25 \%$ & 1 & $1 \%$
\end{tabular}




\section{Table 4}

Centre One Average Baseline Child Compliance

\begin{tabular}{|c|c|c|c|c|c|c|c|}
\hline Child & $\begin{array}{l}\text { Average } \\
\text { Compliance }\end{array}$ & Child & $\begin{array}{l}\text { Average } \\
\text { Compliance }\end{array}$ & Child & $\begin{array}{l}\text { Average } \\
\text { Compliance }\end{array}$ & Child & $\begin{array}{l}\text { Average } \\
\text { Compliance }\end{array}$ \\
\hline 1 & $81 \%$ & 4 & $38 \%$ & 7 & $91 \%$ & 10 & $76 \%$ \\
\hline 2 & $49 \%$ & 5 & $65 \%$ & 8 & $76 \%$ & 11 & $89 \%$ \\
\hline 3 & $83 \%$ & 6 & $100 \%$ & 9 & $81 \%$ & & \\
\hline Average & $75 \%$ & & & & & & \\
\hline
\end{tabular}

Table 5

Centre Two Average Baseline Child Compliance

\begin{tabular}{llllll}
\hline Child & $\begin{array}{l}\text { Average } \\
\text { Compliance }\end{array}$ & Child $\begin{array}{l}\text { Average } \\
\text { Compliance }\end{array}$ & Child $\begin{array}{l}\text { Average } \\
\text { Compliance }\end{array}$ \\
\hline 12 & $69 \%$ & 15 & $100 \%$ & 18 & $97 \%$ \\
13 & $87 \%$ & 16 & $100 \%$ & 19 & $100 \%$ \\
14 & $100 \%$ & 17 & $100 \%$ & & \\
\hline Average & $94 \%$ & & & & \\
\hline
\end{tabular}




\section{Table 6}

Centre Three Average Baseline Child Compliance

\begin{tabular}{llll}
\hline Child & $\begin{array}{l}\text { Average } \\
\text { Compliance }\end{array}$ & Child $\begin{array}{l}\text { Average } \\
\text { Compliance }\end{array}$ \\
\hline 20 & $84 \%$ & 23 & $80 \%$ \\
21 & $90 \%$ & 24 & $97 \%$ \\
22 & $94 \%$ & & \\
\hline Average & $89 \%$ &
\end{tabular}

Table 7

Centre Four Average Baseline Child Compliance

\begin{tabular}{cccccccc}
\hline Child & $\begin{array}{l}\text { Average } \\
\text { Compliance }\end{array}$ & Child & $\begin{array}{l}\text { Average } \\
\text { Compliance }\end{array}$ & Child & $\begin{array}{l}\text { Average } \\
\text { Compliance }\end{array}$ & Child & $\begin{array}{l}\text { Average } \\
\text { Compliance }\end{array}$ \\
\hline 25 & $75 \%$ & 31 & $72 \%$ & 37 & $30 \%$ & 43 & $80 \%$ \\
26 & $45 \%$ & 32 & $100 \%$ & 38 & $87 \%$ & 44 & $20 \%$ \\
27 & no data & 33 & $93 \%$ & 39 & $76 \%$ & 45 & $90 \%$ \\
28 & no data & 34 & $100 \%$ & 40 & $66 \%$ & 46 & $90 \%$ \\
29 & $80 \%$ & 35 & $53 \%$ & 41 & $55 \%$ & 47 & $100 \%$ \\
30 & $93 \%$ & 36 & $100 \%$ & 42 & $90 \%$ & 48 & no data \\
\hline
\end{tabular}




\section{Table 8}

Centre Five Average Baseline Child Compliance

\begin{tabular}{lcclcl}
\hline Child & $\begin{array}{l}\text { Average } \\
\text { Compliance }\end{array}$ & Child $\begin{array}{l}\text { Average } \\
\text { Compliance }\end{array}$ & $\begin{array}{c}\text { Child } \\
\text { Average } \\
\text { Compliance }\end{array}$ \\
\hline 49 & $90 \%$ & 51 & $66 \%$ & 53 & $87 \%$ \\
50 & $92 \%$ & 52 & $63 \%$ & & \\
\hline Average & $80 \%$ & & & \\
\hline
\end{tabular}

Table 9

Centre Six Average Baseline Child Compliance

\begin{tabular}{llllll}
\hline Child & $\begin{array}{l}\text { Average } \\
\text { Compliance }\end{array}$ & Child $\begin{array}{l}\text { Average } \\
\text { Compliance }\end{array}$ & Child $\begin{array}{l}\text { Average } \\
\text { Compliance }\end{array}$ \\
\hline 54 & $100 \%$ & 60 & $88 \%$ & 66 & $100 \%$ \\
55 & $100 \%$ & 61 & $100 \%$ & 67 & $100 \%$ \\
56 & $90 \%$ & 62 & $88 \%$ & 68 & $56 \%$ \\
57 & $100 \%$ & 63 & $80 \%$ & 69 & $90 \%$ \\
58 & $100 \%$ & 64 & $64 \%$ & 70 & $100 \%$ \\
59 & $100 \%$ & 65 & $80 \%$ & 71 & $75 \%$ \\
\hline 5
\end{tabular}




\section{Teacher Compliance Probability Ratings}

As a result of the number of children demonstrating high rates of compliance during baseline, observed child compliance was compared with the compliance probability ratings of the teacher (from the compliance probability questionnaire) for each of the 68 children screened. This analysis involved a comparison of children's observed mean rates of compliance in baseline with the average compliance probability rating level (i.e., level 1: 76\%-100\%; level 2: 51\%-75\%; level 3: 26\%-50\%; or level 4: 0\%-25\%) identified by teachers for the same requests. This examination revealed that 40 of the 68 children (59\%) demonstrated mean rates of baseline compliance above the average compliance probability level identified by their teachers on the questionnaire, 25 of the 68 children (37\%) demonstrated rates of baseline compliance within the same average compliance probability level identified by teachers, and only three children demonstrated mean baseline compliance rates below the average compliance probability level identified by their teachers. Thus, teachers' generally perceived children to be less compliance than observations revealed them to be. Teacher compliance probability ratings and children's baseline compliance are illustrated in Figures 1 through 6.

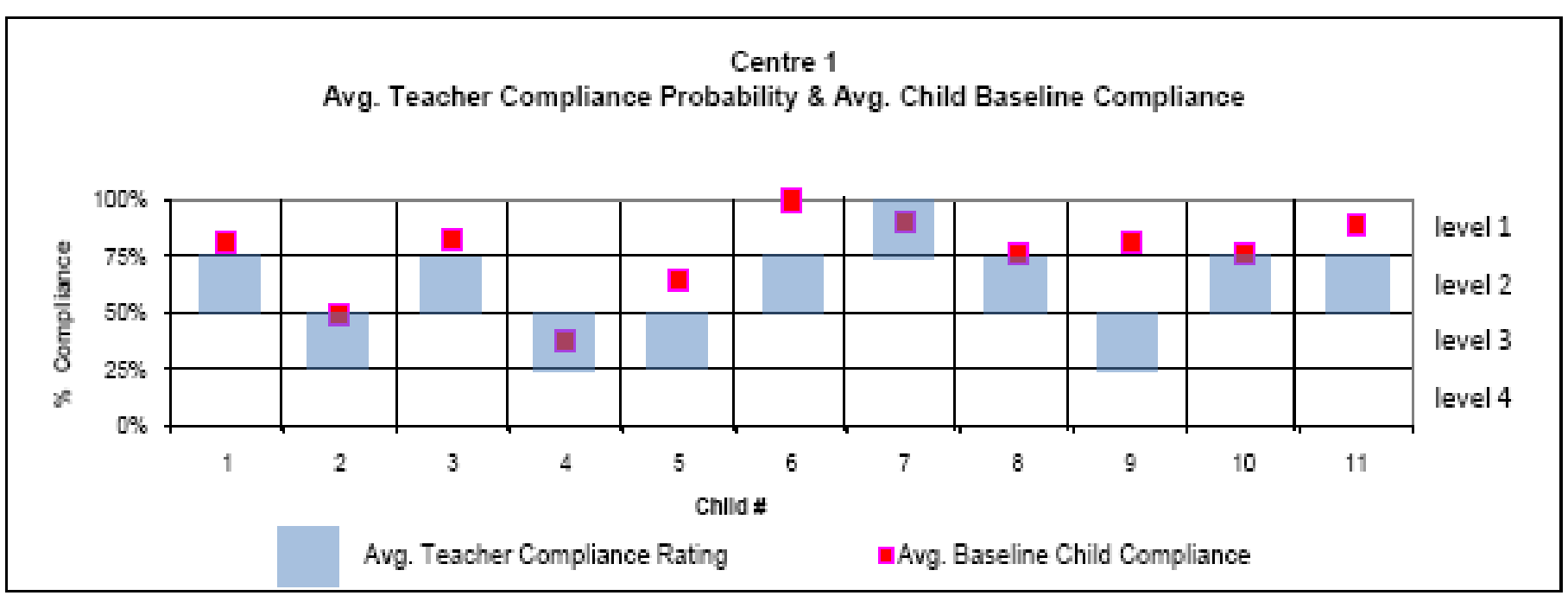

Figure 1 Data points represent average teacher compliance probability rating for requests administered to participant children during baseline phases and observed average baseline child compliance 


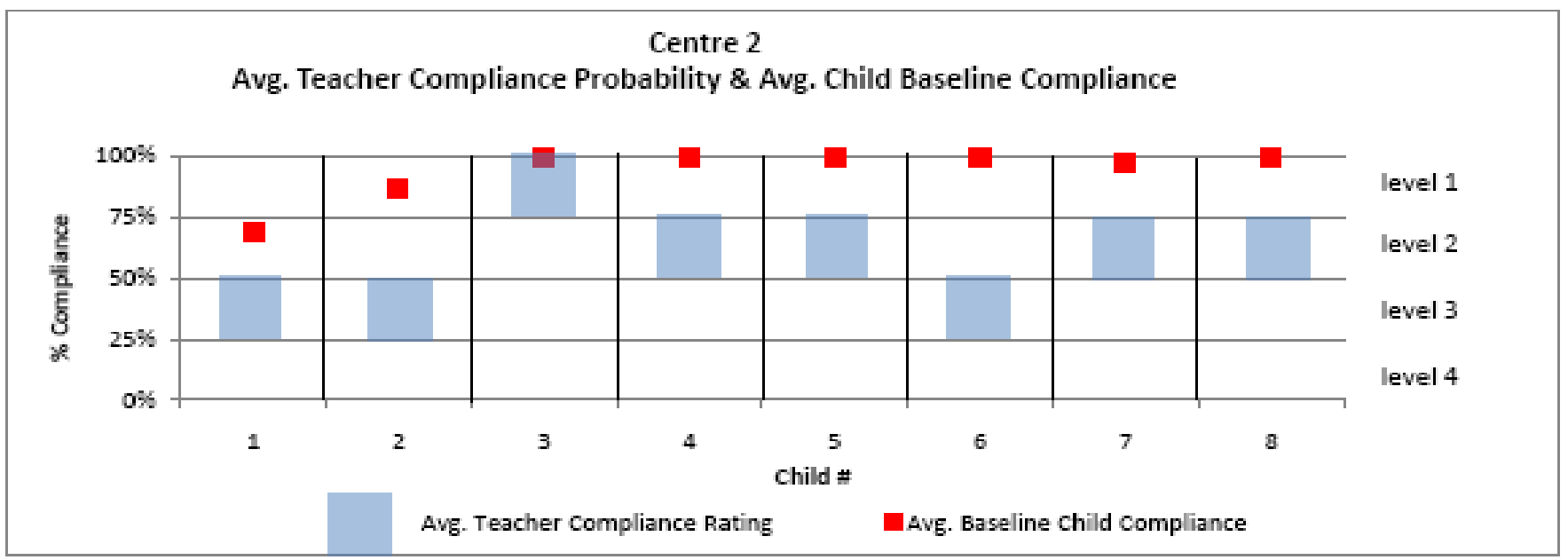

Figure 2 Data points represent average teacher compliance probability ratings for requests administered to participant children during baseline phases and observed average baseline child compliance

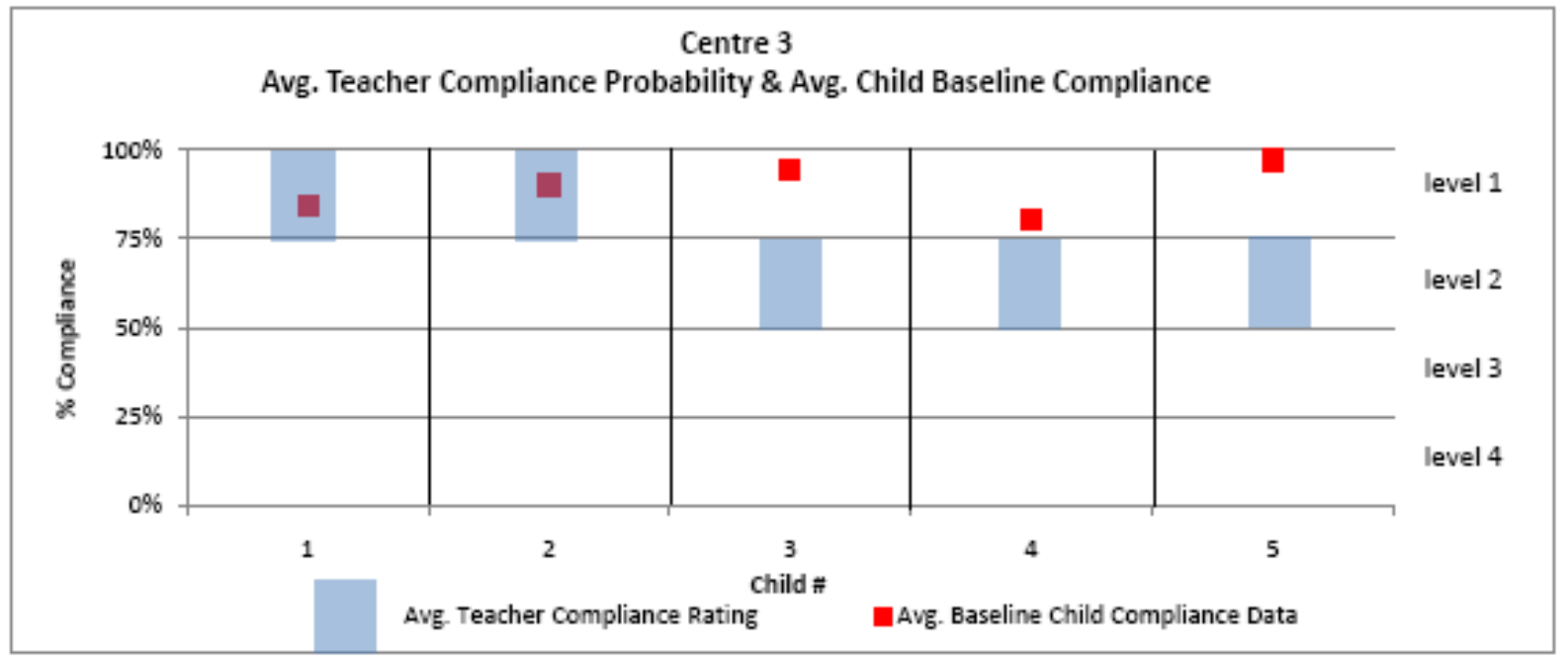

Figure 3 Data points represent average teacher compliance probability ratings for requests administered to participant children during baseline phases and observed average baseline child compliance

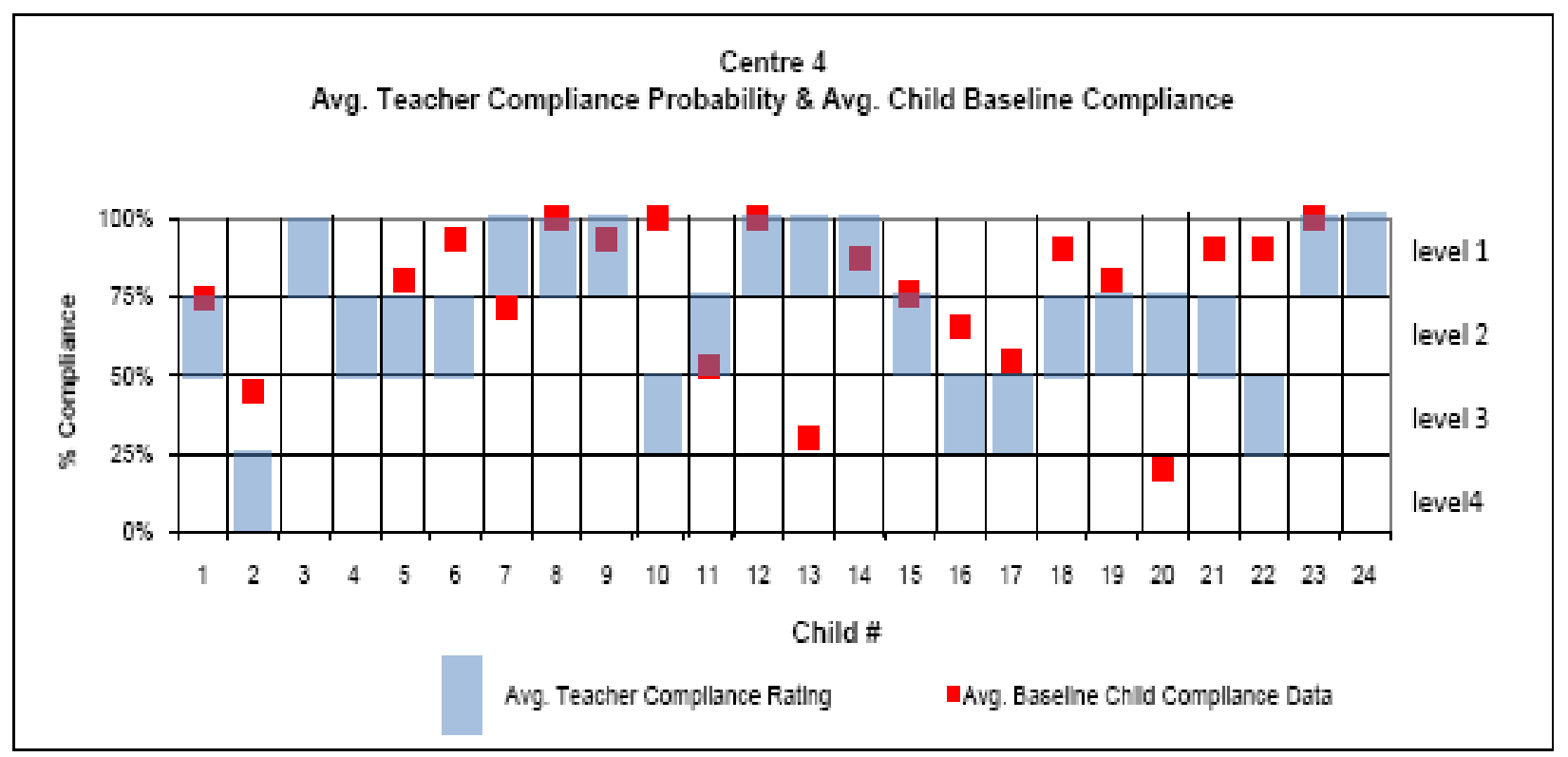

Figure 4 Data points represent average teacher compliance probability ratings for requests administered to participant children during baseline phases and observed average baseline child compliance 
Centre 5

Avg. Teacher Compliance Probability \& Avg. Child Baseline Compliance

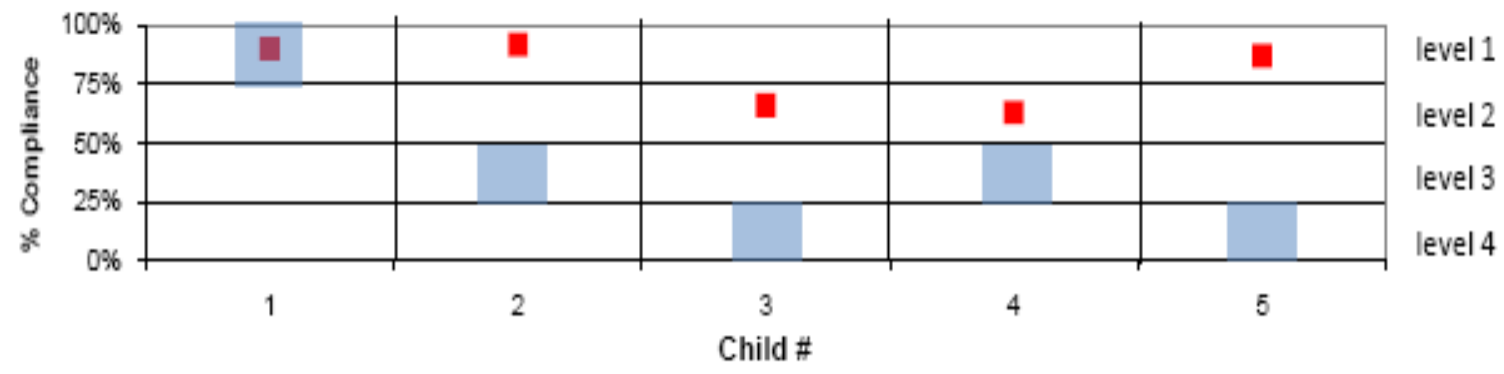

Avg. Teacher Compliance Rating $\quad$ Avg. Baseline Child Compliance Data

Figure 5 Data points represent average teacher compliance probability ratings for requests administered to participant children during baseline phases and observed average baseline child compliance

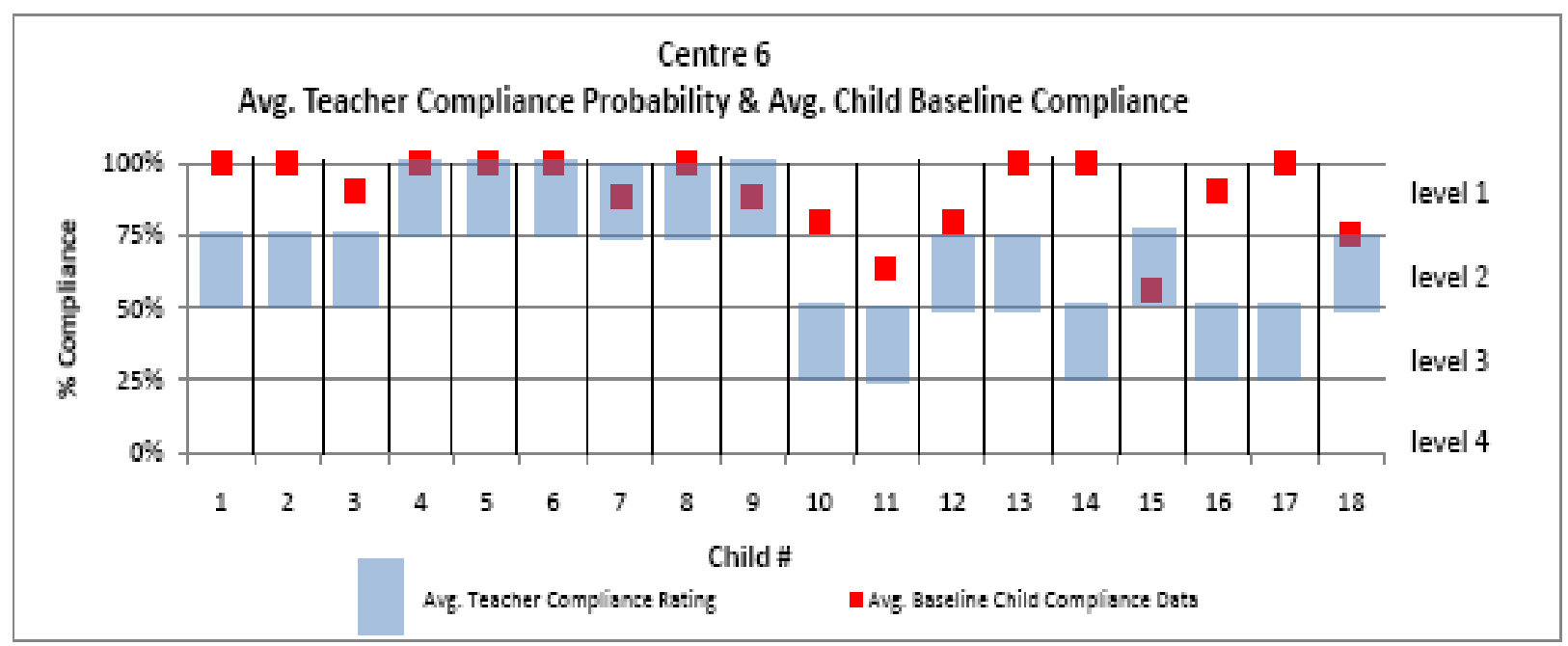

Figure 6 Data points represent average teacher compliance probability ratings for requests administered to participant children during baseline phases and observed average baseline child compliance

\section{Baseline Compliance for Participant Children}

Observational compliance data for the 11 participant children across all phases of the study are presented in Figures 7 through 10. Participating children demonstrated a combined average baseline compliance rate of $56 \%$, with each child presenting varying degrees of difficulty ranging from an average of $20 \%$ to $75 \%$ compliance. 


\section{Play Phase One}

Notwithstanding the wide variance in compliance levels across participant children, all of them demonstrated increased compliance following the introduction of the teacher-child play sessions, improving to a combined average of $88 \%$ (ranging from $74 \%$ to $94 \%$ ). It is of particular note that each of the children independently demonstrated improvement, defined as a mean increase of at least ten percentage points in their mean rate of compliance, during the first play phase when compared to baseline. Across children, improvements ranged from 11 to 56 percentage points above baseline levels.

In addition to improvements in mean child compliance from baseline to play phase one, the participant children demonstrated an improved pattern of compliance. Each child demonstrated an increase in the proportion of sessions in which compliance was perfect (i.e., 100\%). Participant children increased from a combined average of $9 \%$ perfect compliance sessions (range of $0 \%$ to $33 \%$ ), to a combined average of $62 \%$ perfect compliance sessions (range of $29 \%$ to $100 \%$ ).

As well, with the exception of one child (i.e., child 8) for whom no baseline scores at $50 \%$ or less were observed, each of the children demonstrated a decrease in the proportion of sessions at $50 \%$ compliance or less from baseline to play phase one. Participant children increased from an average of $46 \%$ of data points at $50 \%$ or less compliance during baseline (range of $11 \%$ to $75 \%$ ), to an average of $6 \%$ of data points at $50 \%$ or less compliance during the play phase (range of $0 \%$ to $25 \%$ ). 


\section{Withdrawal Phase}

Following the withdrawal of the play sessions, six of the 11 children demonstrated levels of compliance that were equal to or higher than the first play phase, resulting in the cessation of data collection procedures for those participants. In contrast, two children (i.e., child 6, 11), demonstrated a decline in compliance scores following the withdrawal of the teacher-child play sessions, compared to their scores in play phase one. Unfortunately, withdrawal phase data were not collected for two participant children (i.e., child 7,8 ) due to the teacher being unexpectedly transferred to another child care classroom, and only one data point was collected for another participating child (i.e., child 5) before the child was withdrawn from the centre.

\section{Play Phase Two}

As a result of the observed decline in child compliance scores during the withdrawal phase when compared to the play phase, a second play phase was introduced for participant children 6 and 11. Following the re-introduction of the teacher-child play sessions, improvements in compliance were re-established for both children, with average compliance scores returning to levels comparable to the first play phase. The combined mean rate of compliance for these children improved from $48 \%$ during baseline, to $91 \%$ during this play phase.

\section{Play Fading Phase}

During the subsequent play fading phase, both children (i.e., 6, 11) maintained improved levels of compliance when compared to withdrawal and baseline phases. The combined mean rate of compliance for these children was $94 \%$ during the play fading phase, compared to $76 \%$ during the withdrawal phase, and $48 \%$ during baseline. 


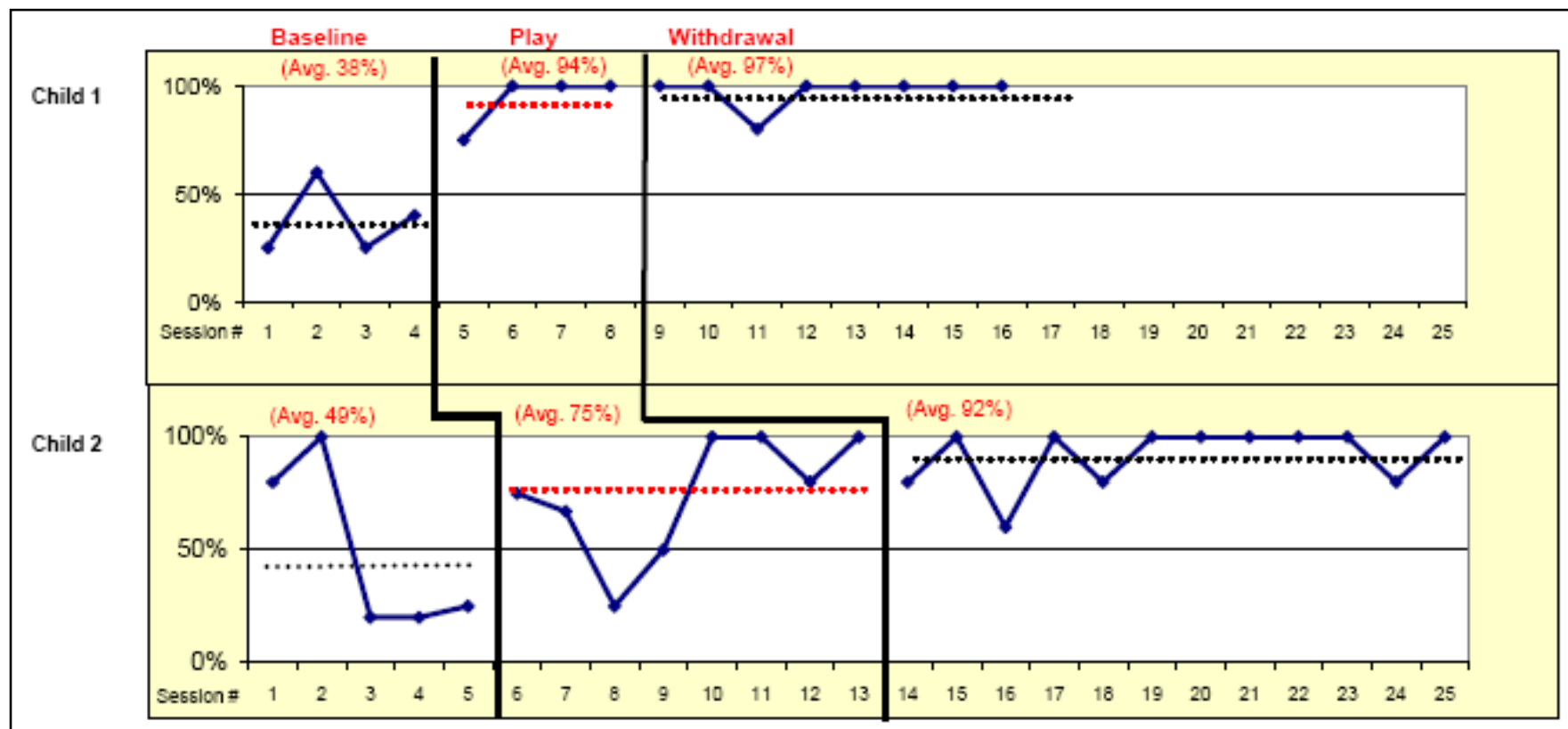

Figure 7 Data points in the graphs represent percent child compliance to requests delivered by participating teachers

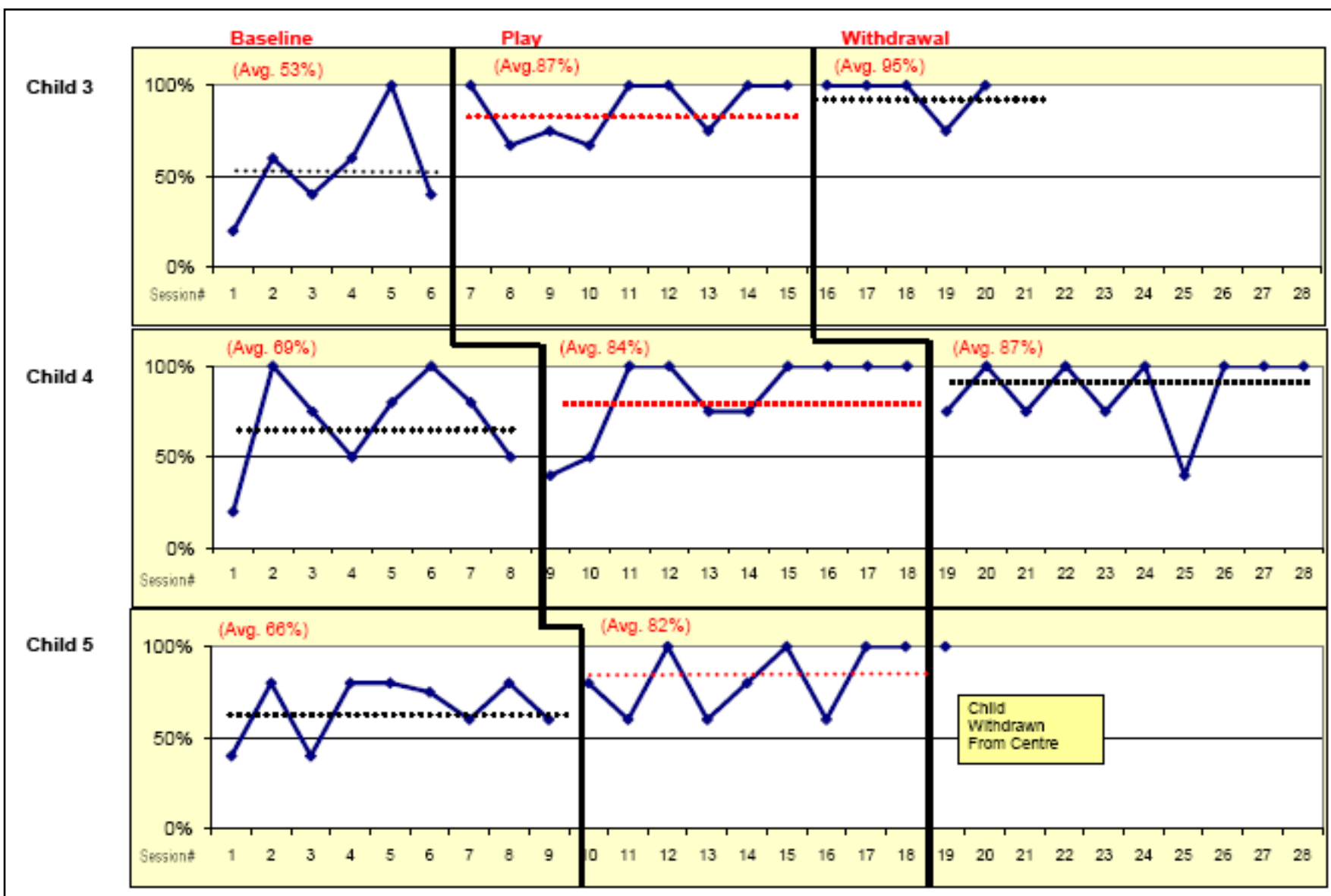

Figure 8 Data points in the graphs represent percent child compliance to requests delivered by participating teachers 


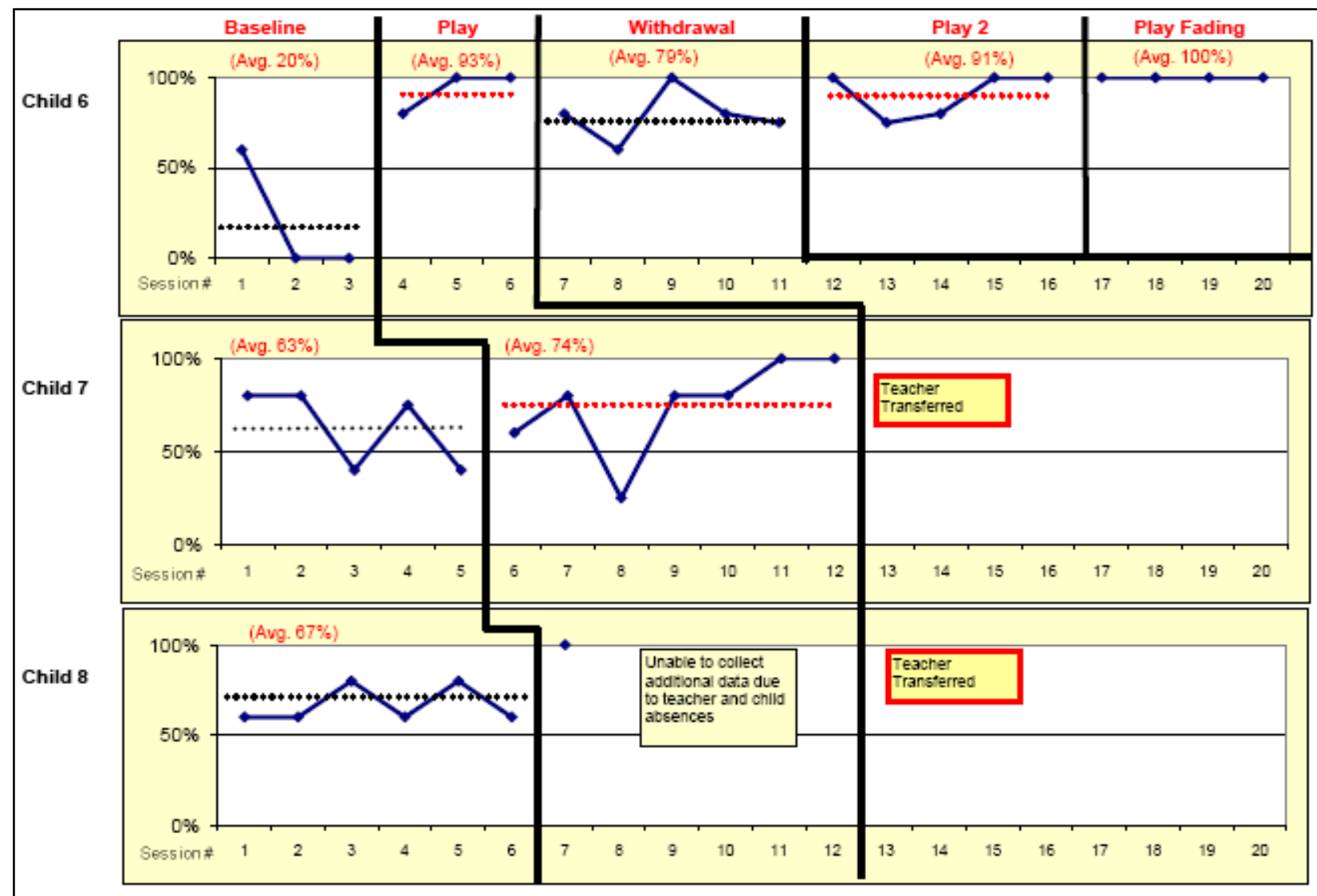

Figure 9 Data points in the graphs represent percent child compliance to requests delivered by participating teachers

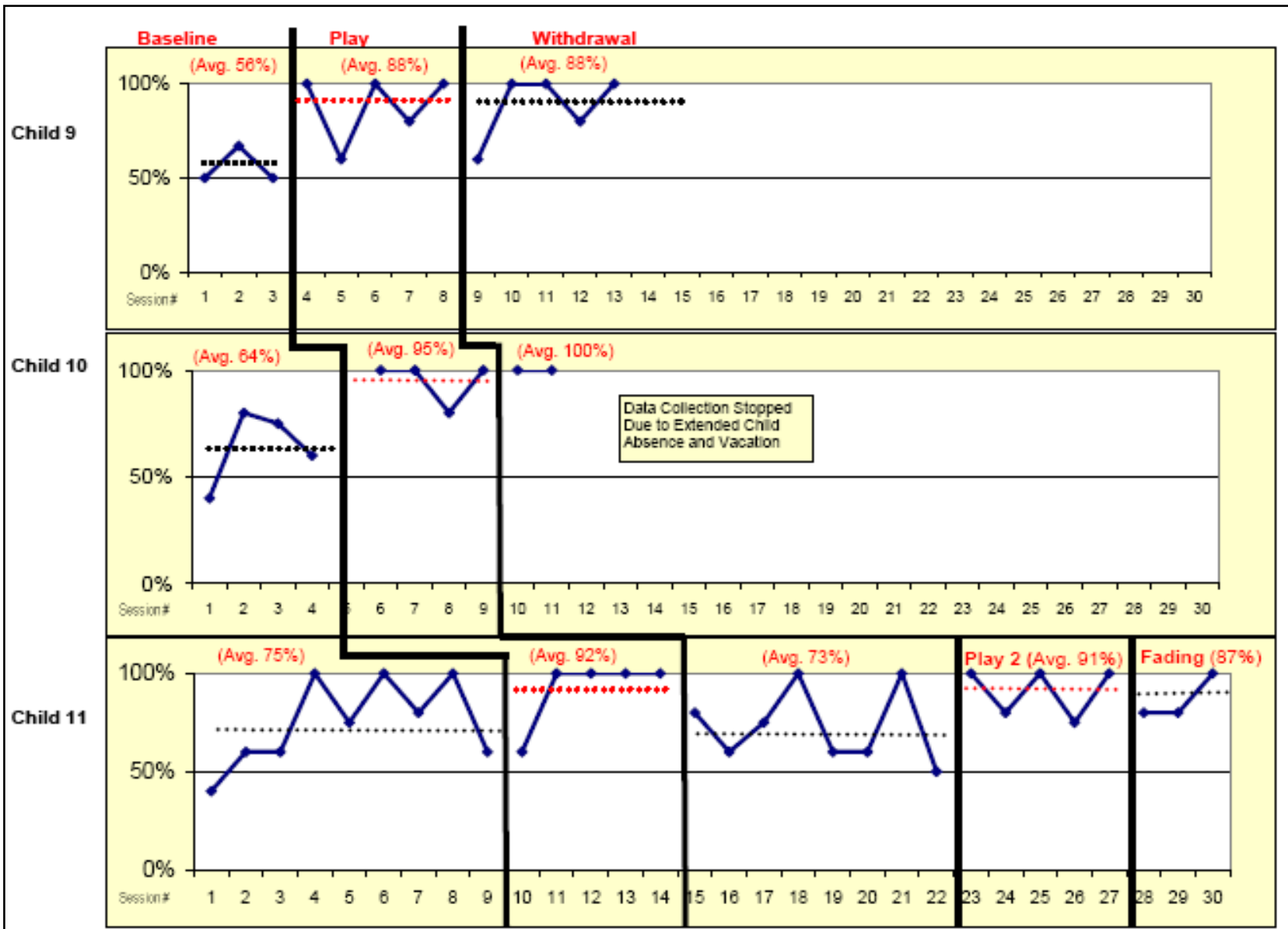

Figure 10 Data points in the graphs represent percent child compliance to requests delivered by participating teachers 


\section{Teacher-Child Classroom Interaction}

During randomly selected observation sessions within each phase of this study, the researcher observed positive teacher-child classroom interactions that occurred naturally between participant teachers and children outside of the teacher-child play sessions. Teacher-child positive interactions are presented in Figures 11 through 21. During baseline, an average of 10\% of each observation period involved positive teacher-child interactions (range of $2 \%$ to $15 \%$ across participant children). Following the introduction of the play phase, positive teacher-child interactions remained at approximately the same level (i.e., $9 \%$; range $=2 \%$ to $17 \%$ ). During the withdrawal phase, positive interactions increased slightly to an average of $12 \%$ of each observation period (range of $4 \%$ to $22 \%$ across children). When examining individual patterns of positive interaction between participant teachers and children, increased positive interactions were observed during withdrawal phases in five of the eight teacher-child pairs for which withdrawal phase data was collected.

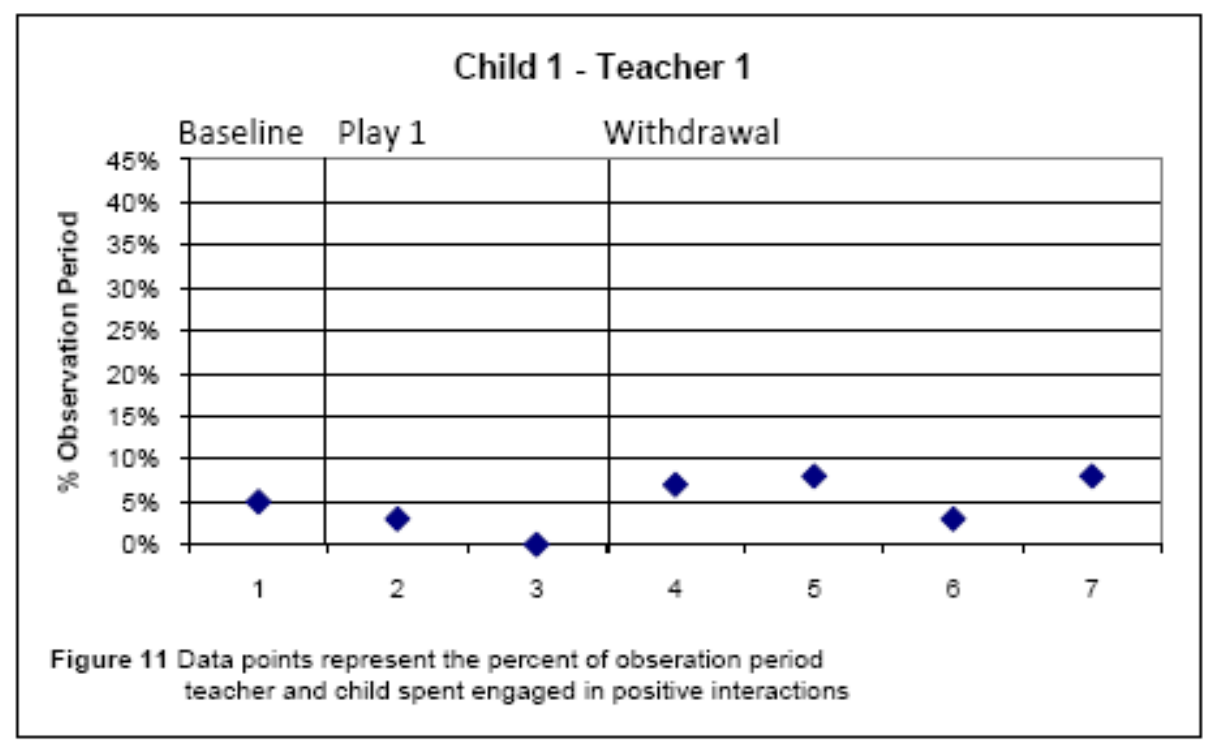




\section{Child 2 - Teacher 1}

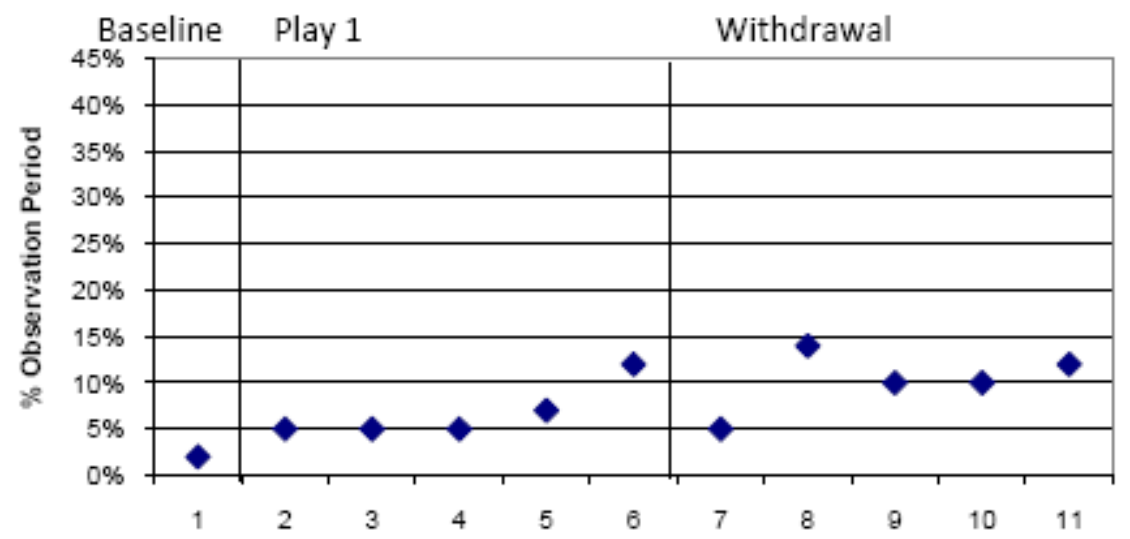

Figure 12 Data points represent the percent of observation period teacher and child spent engaged in positive interactions
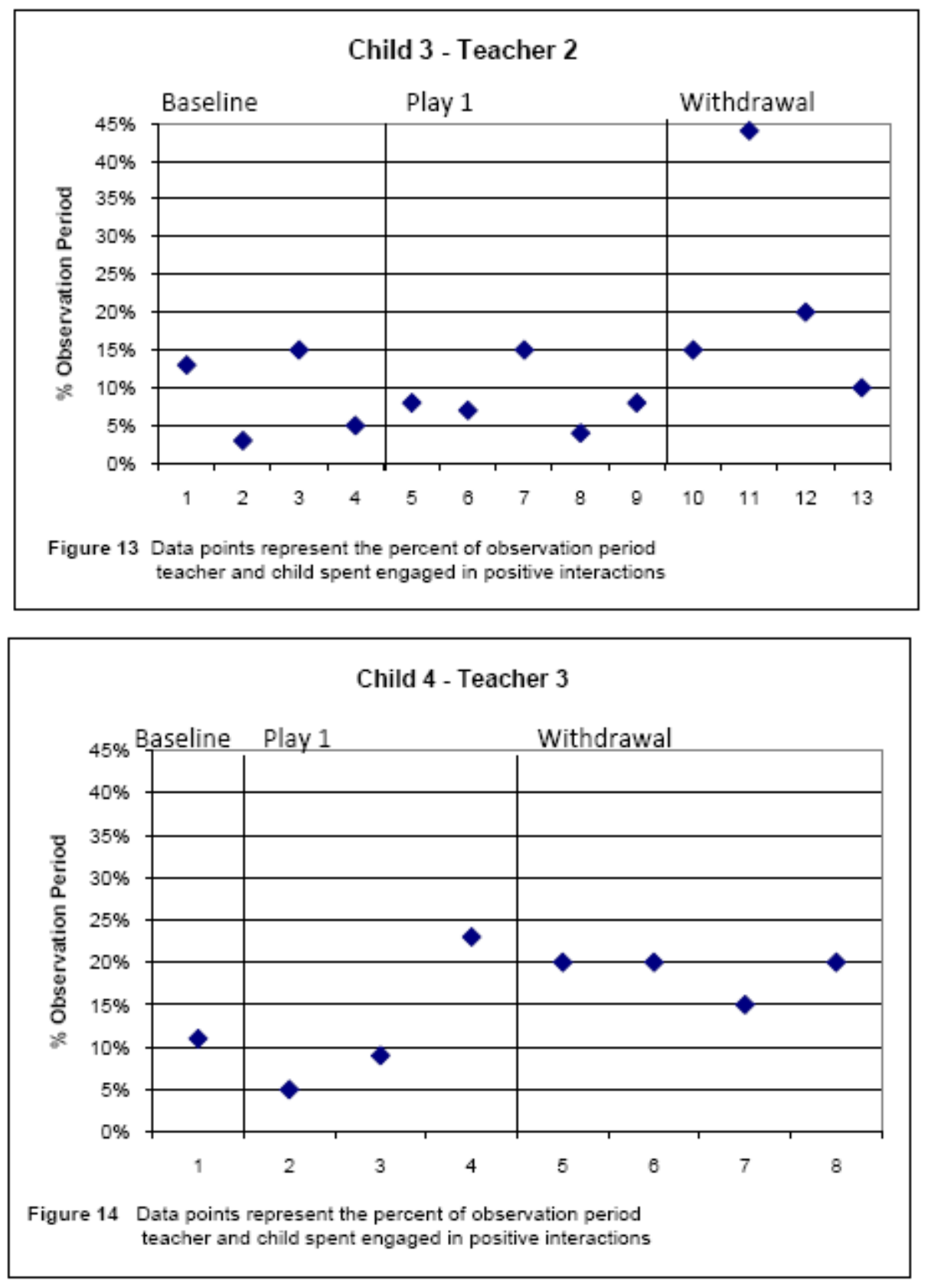

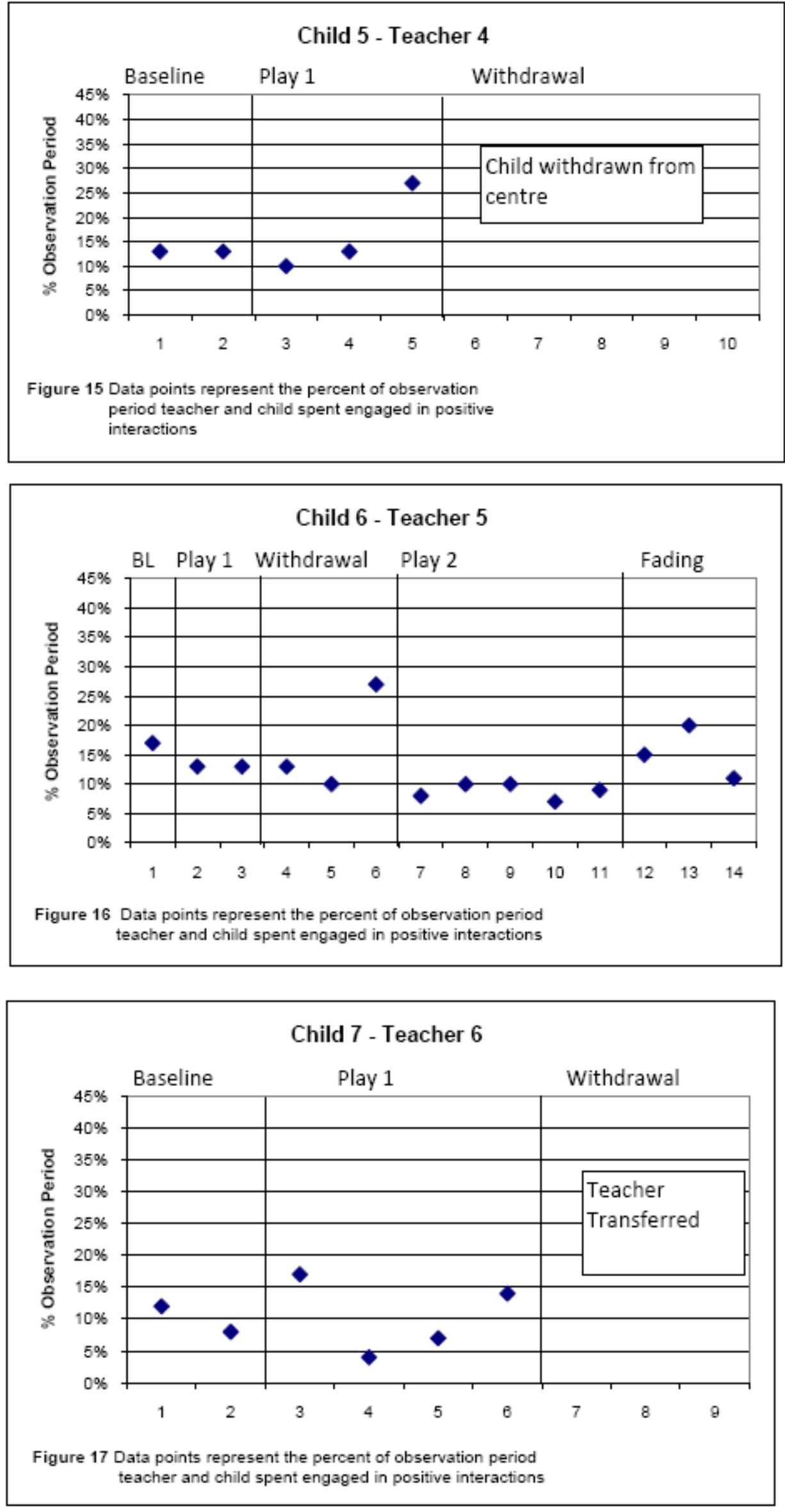


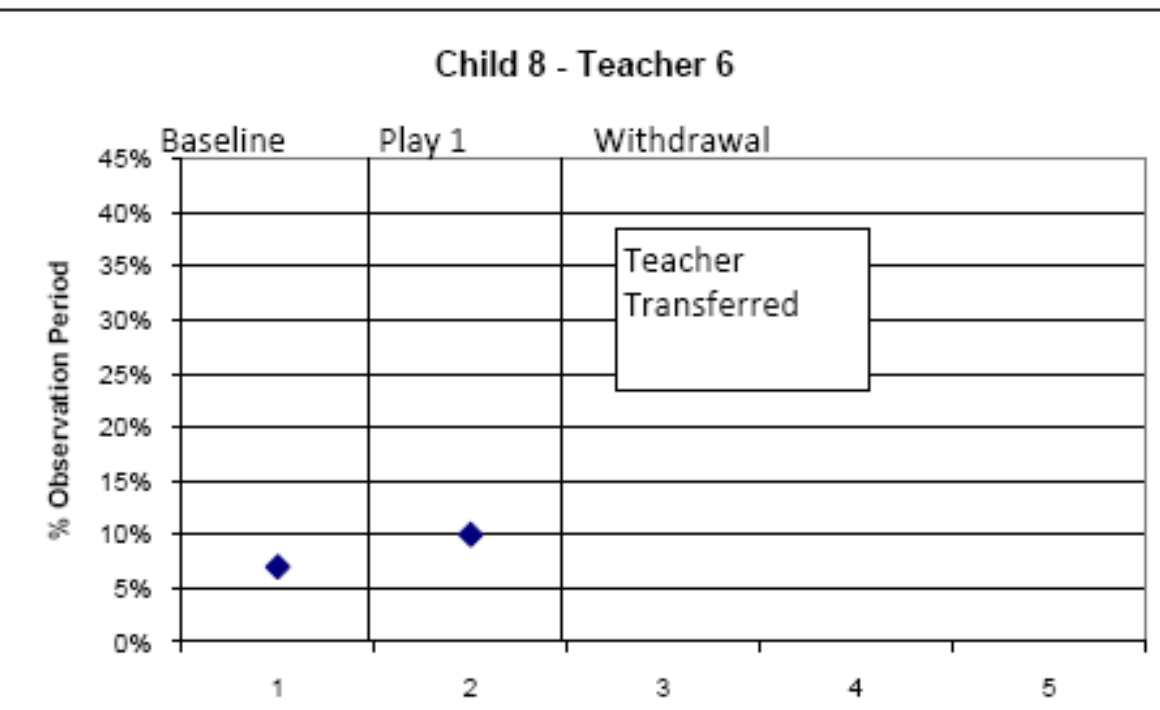

Figure 18 Data points represent the percent of observation period teacher and child spent engaged in positive interactions
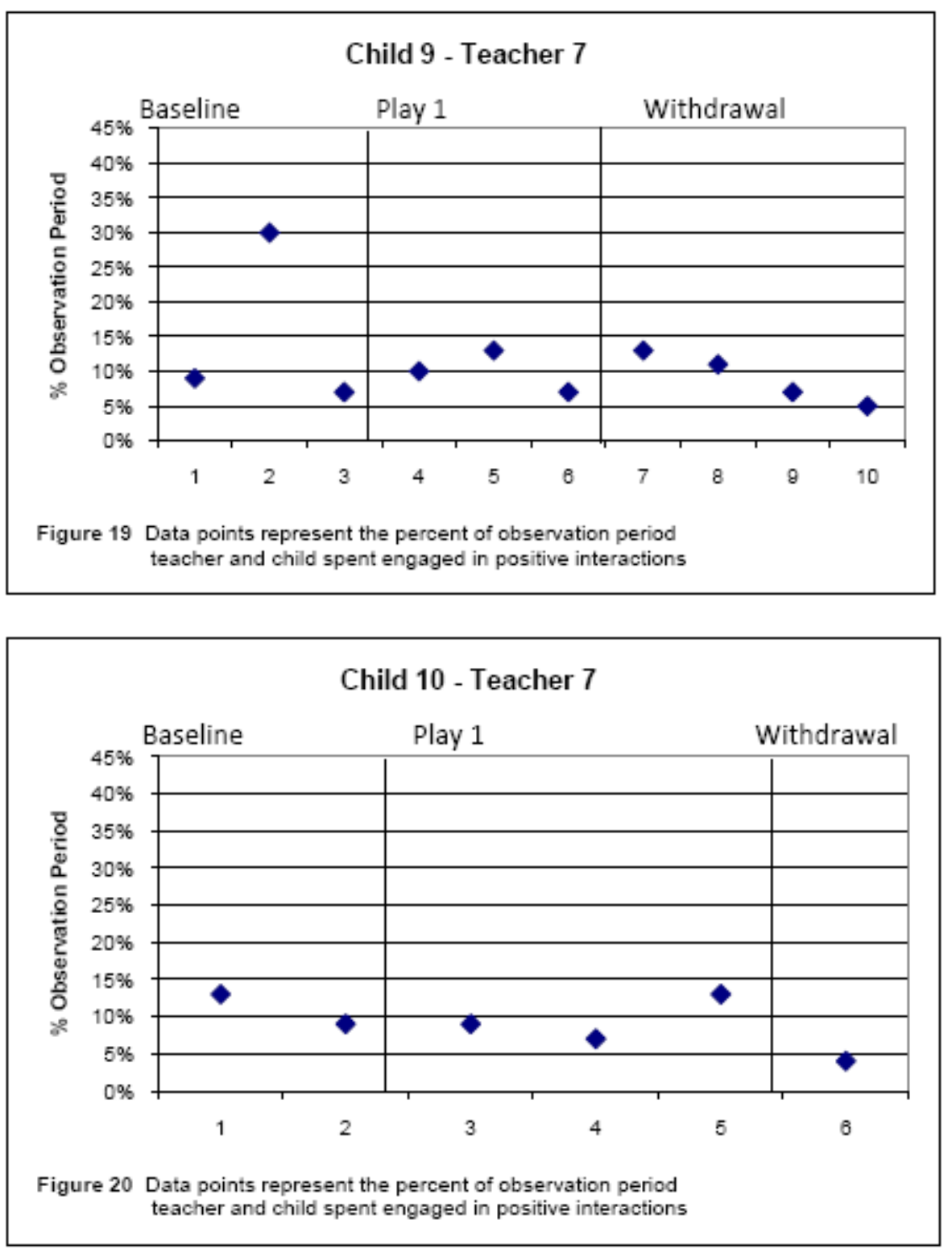


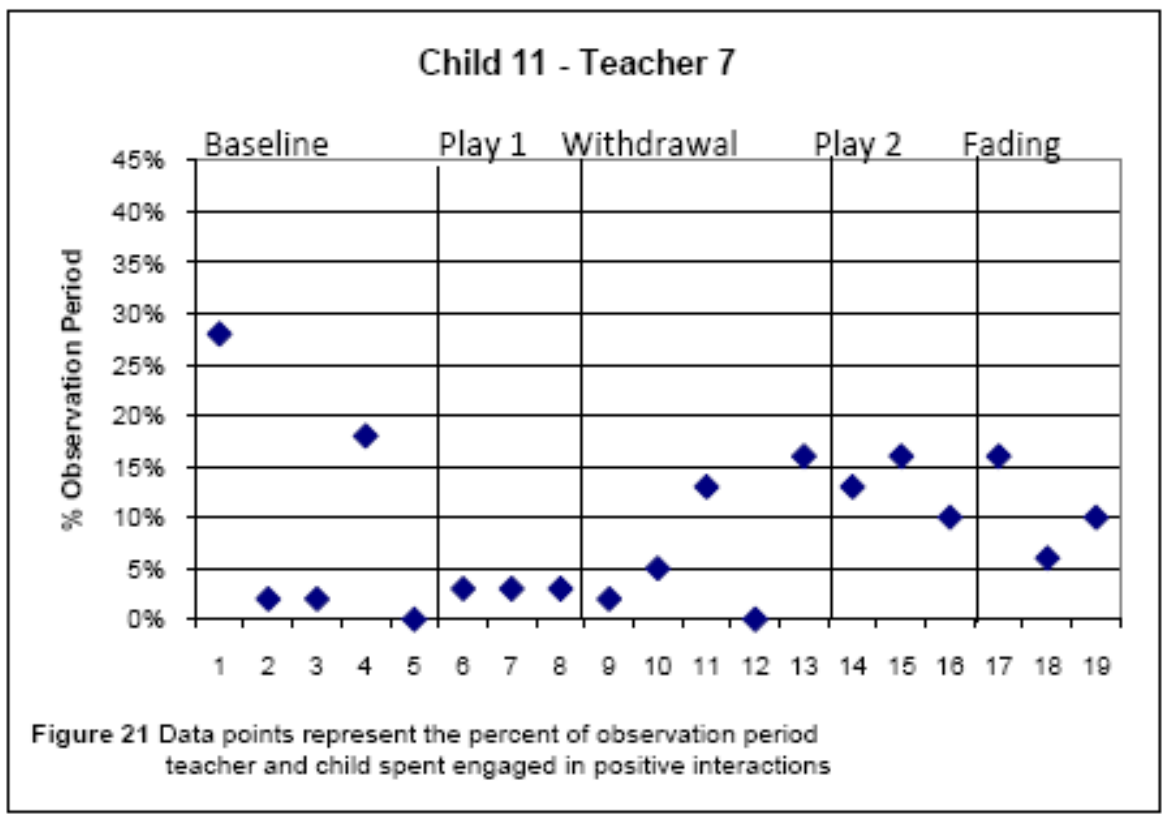




\section{CHAPTER FOUR: DISCUSSION}

The purpose of this study was to evaluate the effect of brief teacher-child play sessions on preschool age children's compliance to teacher requests in child care classrooms. There were two primary findings. First, the introduction of the daily teacher-child play sessions was associated with increased levels of child compliance. This effect was replicated in all of the children who received the play intervention across six classrooms in five separate child care centres. Second, following the withdrawal of the teacher-child play sessions, only two children demonstrated rates of compliance lower than that achieved in the play phase. Due to this decrease in child compliance, a second play phase and a play fading phase were conducted for both children. Following re-introduction of the play sessions, improved levels of compliance were reestablished for both children and maintained during play fading.

\section{Improved Child Compliance}

Participating children were experiencing varying degrees of recurring behavioural difficulties at the start of the study, ranging from mild incidents of uncooperative behaviour (i.e., compliance averaging around $75 \%$ ) to severe levels of non-compliance (i.e., averaging around $20 \%$ ) in their child care classrooms. Regardless of age, gender, and level of compliance difficulties, each child demonstrated improved rates of compliance following the introduction of the teacher-child play sessions, with all children improving to within or above normative levels (e.g., between $70 \%$ to $80 \%$, Whiting \& Edwards, 1988) without any apparent demographic differences being noted.

During baseline phases, recurring patterns of compliance difficulties were observed for almost every participant child. These difficulties did not appear to improve over the course of 
baseline periods, notwithstanding the varying baseline durations arranged for each child to fulfill multiple baseline design requirements. In general, consistent improvements in compliance occurred for each child only after the introduction of the play sessions. Given that the play sessions were introduced in participating classrooms at varying times of the school year (e.g., September, November, January, March, May), the finding of improved compliance only after initiation of play appears to rule out any possibility that compliance increased due to children acclimating to the classroom environment or the disciplinary style of the teacher.

The improved rates of compliance across participant children are of particular significance as they were brought about without strategies commonly used to address children's compliance difficulties, such as reward procedures for prosocial responding or reductive/punishment strategies to decrease non-compliance (e.g., Barkley, 1997; Forehand \& McMahon, 1981). School or daycare staff commonly require behaviour management courses or many hours of training in such procedures to learn how to improve child behaviour. Training in the use of the play intervention was simple and brief, requiring a total of only 30 minutes of training time per teacher.

Additionally, the play sessions themselves were short, requiring only five minutes per day per child to implement. These sessions were not immediately proximal to the behavioural changes produced, allowing the teacher to conduct the sessions whenever they had the time, rather than based on the behaviour of the child. Thus, improvements in child compliance occurred with little teacher effort or time and without altering existing classroom routines, making this an efficient and practical approach for busy child care classrooms. 
There are several potential contextual factors, including ecological and stimulus control variables that may account for the observed improvement in children's compliance during the play phases, when compared to baseline.

\section{Ecological Variables}

During rapport-based play sessions, the teacher created a context in which interactions with the student consistently comprised praise, warmth, responsiveness and few critical reactions to child responses. Within this context, interactions with, and attention from, the teacher may have acquired more potent reinforcement value for participant children, as they grew to enjoy the pleasant time spent with this caring adult. The increased value of the teacher as a reinforcer may have enhanced child motivation to demonstrate those behaviours that resulted in greater access to these pleasant interactions (e.g., compliance and cooperation). Thus the play may have served as an establishing operation (i.e., an antecedent variable that altered the reinforcing effectiveness of behavioural consequences, Michael, 2000), for child compliance, increasing the incentive for the child to demonstrate these behaviours.

\section{Stimulus Control}

Another explanation for the improvement in child compliance involves the concept of stimulus control. Prior to the introduction of teacher-child play, teacher directives often resulted in child non-compliance and teachers commonly responded with reprimands or other corrective responses. The initiation of play sessions created daily opportunities for the teachers to engage in pleasant interactions with the children in the context of prosocial play behaviour. As noted above, these rewarding teacher responses may have served as positive reinforcement for child pro-social behaviour, thereby establishing a new pattern of teacher-child interaction. The 
children came to learn that pro-social and cooperative behaviour was noticed and reinforced by the teacher during the play sessions and were therefore more likely to cooperate in the company of that teacher. The teacher may have become a signal to the children that positive reinforcement and attention were available when cooperation occurred. Thus the teacher became a discriminative stimulus that established stimulus control over child compliance, and the child was more likely to comply in the presence of this stimulus, even outside of play sessions.

\section{Combination of Stimulus Control and Ecological Variables}

It is plausible that the combination of stimulus control and ecological variables contributed to the observed improvement in child compliance. As noted above, participation in the play sessions likely resulted in the teacher becoming a discriminative stimulus for the availability of praise and positive attention (i.e., positive reinforcement) contingent on child prosocial behaviour. Given that the potency of that attention as a positive reinforcer was also greatly enhanced through the play sessions, the motivation for the child to display cooperative behaviour in the presence of the teacher was also increased. As such, the play sessions may have helped establish the availability of teacher attention through stimulus control variables and child motivation to access that attention through ecological variables; this combination may have worked to maintain child compliance following the withdrawal of the play sessions.

\section{Maintenance of Child Compliance After Withdrawal of Play}

Following the withdrawal of the teacher-child play sessions, seven of the nine children for whom withdrawal phase data were collected maintained elevated compliance levels. It is important to note that the current study protocol did not control for the manner in which teachers interacted with children outside of the short play sessions or during the withdrawal phase. 
Instead, teachers were instructed to simply interact with children as they naturally would in their classrooms. This decision was made to provide the opportunity for an initial consideration of the likelihood that the play sessions altered the manner in which teachers interacted with students during the remainder of their school day.

The teacher-child interaction data, although informal, suggests that an increase in positive interactions may have occurred for most of the children during the withdrawal phases, when compared to the play phases. During the withdrawal phases, these interactions may have contributed to the maintenance of child compliance, ensuring that teachers continued to serve as a discriminative stimulus for positive teacher attention and sustaining children's motivation to respond cooperatively in the presence of their teachers.

However, it should also be noted that for some of the children whose compliance maintained after withdrawal of play sessions, there was no increase in positive teacher-child interactions during the withdrawal phase; these children still maintained high levels of compliance, raising the possibility that maintenance of compliance may be related to other variables. One possibility is that, once established as a highly potent reinforcer for children's pro-social behaviour, teacher praise and positive attention, even in small dosages, may have sustained the motivation of these children to cooperate with teacher requests.

Only two children (child 6 and 11), demonstrated decreases in compliance following the withdrawal of the play sessions. This decline in pro-social responding warranted introduction of a second play phase for these two children in an attempt to recapture the gains that had been made in the first intervention phase. It is important to highlight that the compliance levels for 
these two children in the withdrawal phase, although lower than in the previous play phase, did not decline to problem levels for either child.

Child 6 demonstrated the lowest levels of baseline compliance compared to the other participant children and made substantial gains in the play phase. During the withdrawal phase, this child's compliance remained well above baseline rates and within normative levels. In contrast, Child 11 demonstrated the highest rate of baseline compliance amongst participant children (compliance was not at serious problematic levels before training, but had some small potential for improvement). Compliance for this child increased to near perfect levels in the play phase. In the withdrawal phase, compliance decreased to levels similar to those in baseline, where compliance was not a significant concern.

It is interesting to note that, although both of these children demonstrated some reversal of compliance gains in the withdrawal phase, both were able to maintain high compliance levels after the second play phase was introduced and faded. This finding suggests that, compared to the other participants, these two children required longer durations of time engaged in teacherchild play before they began to view their teacher as a potent source of reinforcement or as someone who was likely to notice and consistently reinforce compliant responses with attention or praise outside of play sessions. This may have been due to specific child characteristics such as learning style, developmental history, behavioural diagnostic issues, and/or environmental variables such as historical patterns of interaction with teachers and other adults (e.g., parents).

Additionally, the gradual and systematic fading of the play sessions may have contributed to the maintenance of improved compliance for both of these children. Fading procedures typically entail the systematic altering of stimuli that control a response so that the response 
gradually becomes controlled by modified or new stimuli (Martin \& Pear, 1996). For example, stimulus fading may involve gradually withdrawing elements of a treatment program while systematically introducing more natural conditions after behavioural gains have been achieved. The goal of such an endeavour would be to ensure that the improved behaviour comes under the stimulus control of naturally occurring circumstances rather than artificial treatment conditions (which typically cannot be maintained indefinitely).

In the current study, the abrupt withdrawal of the play intervention and sudden return to a more natural classroom context without playful interactions following the initial play phase may have contributed to the regression in compliance in these two children. The systematic fading of the teacher-child play sessions after the second play phase however, likely played a role in the maintenance of these two children's high levels of compliance by allowing for the gradual transfer of stimulus control from the play intervention to natural classroom conditions. Thus, after fading, stimulus control of child compliance was expanded from the narrow play session conditions to the much broader array of circumstances in the everyday classroom environment.

\section{Limitations and Considerations for Future Research}

There are several limitations that should be considered when interpreting the findings of this study. While treatment effects were replicated across children in five separate child care centres, these effects were demonstrated with a relatively small sample of children and could be further substantiated with a larger sample in a control group design. The time series nature of the research design in the present study, however, provided intensive information about the process of change with the introduction and withdrawal of teacher-child play sessions in a child care classroom. Thus, this study served as an important precursor to a larger, group comparison investigation. 
Further, given that the teacher-child classroom interaction data were exploratory in nature, these observations were not conducted with the rigor required to draw firm conclusions about the effects of the teacher-child play sessions on the behaviour of the teacher. Moreover, given the limited time and resources available to do extensive observations, this data set offered a very small window of observation of the interactions of teacher and student. Future studies should involve a more comprehensive data collection procedure that includes more extensive observation periods and inter-observer reliability checks. For example, obtaining videotaped footage of naturally occurring classroom teacher-child interactions throughout baseline, play, and withdrawal phases would allow for more comprehensive and rigorous coding and analysis of any effects rapport-based play may have on teacher behaviours (e.g., occurrence of praise statements, time spent in play with children, the use of punishment procedures), and child behaviours (e.g., initiation of play with teacher, decrease in classroom problem behaviours, acquiescence with teacher and peer requests), prior to, during, and following play conditions.

On a related point, observations in the current study were not conducted by an independent observer who was able to remain blind to experimental conditions (i.e., the author conducted both interobserver agreement checks on the teacher-collected compliance data and the observations of teacher-child interactions outside of compliance situations). With regard to teacher-collected compliance data however, high rates of inter-observer reliability between the author and participant teachers across classrooms and child care centres increases confidence that the fidelity of the child compliance data was high.

Another limitation of the present study relates to maintenance of intervention effects. This investigation demonstrated that improvements in child compliance were maintained in the days following the withdrawal of the play sessions. It is not known however, how long after the 
cessation of the play sessions improvements in child compliance were sustained. Future research should include post-intervention follow-up measures to provide an evaluation of the extent of maintenance of compliance effects after play sessions.

In addition, we did not examine whether teacher-child play sessions resulted in generalized improvements in child compliance to adults not directly involved in the play sessions or to settings other than the child care classroom where the intervention took place. It would be of interest to conduct probes with other teachers in other settings to determine whether child cooperation extended beyond the circumscribed stimulus conditions present during play.

To better understand the effects of the play intervention, it would also be useful to examine, using questionnaires or interviews, any changes in teachers' and children's perception of one another and their relationship following play sessions. Based on the findings of the current study, one might predict that children and teachers would come to hold more positive views of one another as they spend enjoyable time together during play. Such information might provide further elucidation of the improved compliance that occurred in the present study.

The current study highlights the need for further examination of teachers' perceptions of children's classroom compliance difficulties. Although teachers reported compliance to be problematic for most of the children in their classrooms prior to the start of the study, baseline data collection revealed that the majority of children were demonstrating high rates of compliance. Teacher adherence to specific request delivery procedures such as those utilized in this study (i.e., obtaining child's attention, close proximity to child, one-step instruction) may have contributed to the high rates of baseline child compliance by lessening demands placed on children (e.g., removing multiple-step instructions, allowing adequate time for children to 
respond), and reducing classroom distractions that may reduce child compliance (e.g., ensuring children were attending to the request and were not engaged in a classroom activity at the time the request was delivered). However, it is also possible that teachers tended to perceive students as more oppositional than they were. Within busy pre-school child care classrooms, even mild and occasional child compliance difficulties can be extremely disruptive to the classroom, as teachers work to complete scheduled activities, transition from one activity or setting to the next, and attempt to adhere to fixed daily timetables and routines. In this demanding context, teachers may view sporadic non-compliance, even within developmentally appropriate levels, to be extremely distressing, and therefore may report compliance difficulties to be occurring at a rate higher than the actual frequency of such behaviour.

The participants in this study represented a non-clinical sample of preschool children. Investigation of this intervention approach with children from specific diagnostic groups (e.g., oppositional defiant disorder, attention deficit disorder, developmental disabilities) would help to determine the extent to which the present findings can be generalized to more challenging clinical problems. Such studies would help to determine whether the play intervention used in the current study has potential as a stand-alone intervention for children who have been referred for treatment or special classroom placements due to severe oppositional and other behavioural difficulties.

In spite of these limitations, the current study illustrates the substantial effect that positive teacher-child interactions can have on children's pro-social behaviour. By simply altering the manner in which they interact with the children in their care for a few minutes each day, teachers may be able to prevent the onset of compliance difficulties, reduce the need for reactive, punitive responses to child misbehaviour, and create a classroom environment that promotes and sustains 
children's pro-social behaviour. While rapport-based play is a departure from more traditional reactive techniques used to address children's non-compliant behaviour, within busy child care environments these short teacher-child play sessions provide teachers with a simple, pro-active, and non-intrusive strategy for improving children's compliance. 


\section{References}

Alkon, A., Ramler, M., \& MacLennon, K. (2003). Evaluation of mental health consultation in child care centers. Early Childhood Education Journal, 31(2), 91-99.

Anderson, J.C. (1994). Epidemiological issues. In T.H. Ollendick, N.J. King, \& W. Yule (Eds.), International handbook of phobic and anxiety disorders in children and adolescents (pp. 43-65). New York: Plenum Press.

Arnold, D.H., Griffith, J.R., Ortiz, C., \& Stowe, R.M. (1998). Day care interactions and teacher perceptions as a function of teacher and child ethnic group. Journal of Research in Childhood Education, 12, 143-154.

Arnold, D.H., Ortiz, C., Curry, J.C., Stowe, R.M., Goldstein, N.E., \& Fisher, P.H. (1999). Promoting academic success and preventing disruptive behaviour disorders through community partnership. Journal of Community Psychology, 27, 589-598.

Austin , J.L., \& Agar, G. (2005). Helping young children follow their teachers' directions: The utility of high probability command sequences in pre-K and kindergarten classrooms. Education and Treatment of Children, 28, 222-236.

Austin, J.L., \& Soeda, J.M. (2008). Fixed-time teacher attention to decrease off-task behaviours of typically developing third graders. Journal of Applied Behavior Analysis, 41, 279-283.

Bacon, E.H. (1990). Using negative consequences effectively. Academic Therapy, 25(5), 599-611.

Barkley, R. (2000). Commentary: Issues in training parents to manage children with behavior problems. Journal of the American Academy of Child and Adolescent Psychiatry, 39, 1004-1007. 
Barkley, R.A. (1997). Defiant children: A clinician's manual for assessment and parent training ( $\left.2^{\text {nd }} e d.\right)$. New York: Guilford Press.

Barkely, R.A., Shelton, T.L., Crosswait, C., Moorhouse, M., Fletcher, K., Barret, S., et al. (2002). Preschool children with disruptive behaviour: three year outcome as a function of adaptive disability. Development and Psychopathology, 14, 45-67.

Barlow, D., Hayes, S., \& Nelson, R. (1986). The scientist practitioner: Research and accountability in clinical and educational settings. New York: Pergamon Press.

Barlow, D.H., Herson, M. (1984). Single case experimental designs. New York:Pergamon.

Bayer, J.K., Hiscock, H., Ukoumunne, O.C., Price, A., \& Wake, M. (2008). Early childhood aetiology of mental health problems: A longitudinal population-based study. Journal of Child Psychology and Psychiatry 49, 1166-1174.

Bear, G.G. (1998). School discipline in the United States: Prevention, correction, and longterm social development. Educational and Child Psychology, 15, 15-39.

Birch, S.H., \& Ladd, G.W. (1997). The teacher-child relationship and children's early school adjustment. Journal of School Psychology, 35, 61-79.

Boelter, E.W., Wacher, D.P., Call, N.A., Ringdahl, J.E., Kopelman, T., \& Gardner, A.W. (2007). Effects of antecedent variables on disruptive behaviour and accurate responding in young children in outpatient settings. Journal of Applied Behaviour Analysis, 40, 321326.

Bolger, K.E., Patterson, C.J., Thompson, W.W., Kupersmidt, J.B. (1995). Psychosocial adjustment among children experiencing persistent and intermittent family economic hardship. Child Development, 66, 1107-1129. 
Bosquet, M., \& Egeland, B. (2006). The development and maintenance of anxiety symptoms from infancy through adolescence in a longitudinal sample. Development and Psychopathology, 18, 517-550.

Bowlby, J. (1980). Attachment and loss, vol. 3. New York: Basic Books.

Bretherton, I. (1992). The origins of attachment theory: John Bowlby and Mary Ainsworth. Developmental Psychology, 28, 759-775.

Brody, G.H., \& Flor, D.L. (1998). Maternal resources, parenting practices, and child competence in rural, single-parent African American families. Child Development, 69, 803-816.

Buck, K.A., \& Ambrosino, R.J. (2004). Children with severe behaviour problems: A survey of Texan child care centres' responses. Early Childhood Education Journal, 31, 241-246.

Bullock, C., \& Normand, M.P. (2006). The effects of a high-probability instruction sequence and response-independent reinforcer delivery on child compliance. Journal of Applied Behaviour Analysis, 39, 495-499.

Burchinal, M.R., Roberts, J.E., Hooper, S., \& Zeisel, S.A. (2000). Cumulative risk and early cognitive development: A comparison of statistical risk models. Developmental Psychology, 36, 793-807.

Campbell, S.B. (1995). Behaviour problems in pre-school children: A review of recent research. Journal of Child Psychology and Psychiatry, 36, 113-149.

Campbell, S.B., \& Ewing, L.J. (1990). Follow-up of hard-to-manage preschoolers: Adjustment at age 9 and predictors of continuing symptoms. Journal of Child Psychology and Psychiatry, 31, 871-889. 
Carr, E.G., Taylor, J.G., \& Robinson, S. (1991). The effects of severe behavior problems in children on the teaching behavior of adults. Journal of Applied Behavior Analysis, 24, $523-535$.

Cassibba, R., Van Ijzendoorn, \& M., D’Odorico, L. (2000). Attachment and play in child care centres: Reliability and validity of the attachment Q-sort for mothers and professional caregivers in Italy. International Journal of Behavioural Development, 24, 241-255.

Chamberlain, P., \& Patterson, G.R. (1995). Discipline and child compliance in parenting. In Borstein, M.H. (1995). Handbook of Parenting, vol. 4: Applied and practical parenting, (pp. 205-225). Hillsdale, N.J, England: Lawrence Erlbaum Associates Inc.

Conroy, M.A., \& Brown, W.H. (2004). Early identification, prevention, and early intervention with young children at risk for emotional or behavioral disorders: Issues, trends, and a call for action. Behavioural Disorders, 29, 224-236.

Corrigan, L.A. (2006). Impact of a teacher-child rapport building intervention on classroom compliance and maladaptive behaviour in children with behavioural difficulties. Dissertation Abstracts International Section A: Humanities and Social Sciences, 67, pp. 2050.

Crowther, J.H., Bond, L.A., \& Rolf, J.E. (1981). The incidence, prevalence, and severity of behaviour disorders among preschool aged children in day care. Journal of Abnormal Child Psychology, 9, 23-42.

De Kruif, R.E.L., McWilliam, R.A., Ridley, S.M., \& Wakely, M.B.(2000). Classification of teachers' interaction behaviours in early childhood classrooms. Early Childhood Research Quarterly, 15, 247-268. 
Ducharme, J.M. (1999). A conceptual model for treatment of externalizing behaviour in acquired brain injury. Brain Injury, 13, 645-668.

Ducharme, J.M. (1996). Errorless compliance training: Optimizing clinical efficacy. Behaviour Modification, 20, 259-280.

Ducharme, J.M., Atkinson, L., \& Poulton, L. (2000). Success-based, noncoercive treatment of oppositional behaviour in children from violent homes. Journal of the American Academy of Child and Adolescent Psychiatry, 39, 995-1004.

Ducharme, J., Davidson, A., \& Rushford, N. (2002). Treatment of oppositional behavior in children of parents with brain injury and chronic pain. Journal of Emotional and Behavioral Disorders, 10, 241-248.

Ducharme, J.M., \& Diadamo, C. (2005). An errorless approach to management of child noncompliance in a special education setting. School Psychology Review, 34, 107-115.

Ducharme, J.M., \& Harris, K.E. (2005). Errorless embedding for children with on-task and conduct difficulties: Rapport-based, success-focused intervention in the classroom. Behaviour Therapy, 36, 213-222.

Ducharme JM, Popynick M, Pontes E, \& Steele, S. (1996). Errorless compliance to parental requests, III: group parent training with parent observational data and long-term followup. Behaviour Therapy, 27, 353-372.

Ducharme, J.M., \& Rushford, N. (2001). Proximal and distal effects of play on child compliance with a brain injured patient. Journal of Applied Behaviour Analysis, 34, 221-224. 
Ducharme, J.M., \& Worling, D.E. (1994). Behavioural momentum and stimulus fading in the acquisition and maintenance of child compliance in the home. Journal of Applied Behaviour Analysis, 27, 639-647.

Dunlap, G., Kern-Dunlap, L., Clarke, S., \& Robbins, F.R. (1991). Functional assessment, curricular revision, and severe behaviour problems. Journal of Applied Behavior Analysis. Special Issue: Social Validity: Multiple Perspectives, 24, 387-397.

Egger, H.L., \& Angold, A. (2006). Common emotional and behavioural disorders in preschool children: Presentation, nosology, and epidemiology. Journal of Child Psychology and Psychiatry, 47, 313-337.

Essau, C.A. (2003). Epidemiology and Co-morbidity. In Conduct and Oppositional Defiant Disorders: Epidemiology, Risk Factors, and Treatment (pp.33-59). Mawah, N.J.: Lawrence Erlbaum Associates Publishers.

Eyberg, S.M., Boggs, S.R., \& Algina, J. (1995). Parent-child interaction therapy: A psychosocial model for the treatment of young children with conduct problem behaviour and their families. Psychopharmacology Bulletin, 31, 83-92.

Feinfeld, K.A., \& Baker, B.L. (2004). Empirical support for a treatment program for families of young children with externalizing problems. Journal of Clinical and Adolescent Psychology, 33, 182-195.

Forehand, R. (1986). Parental positive reinforcement with deviant children: Does it make a difference? Child and Family Behavior Therapy, 8, 19-25.

Forehand, R. L., \& McMahon, R. J. (1981). Helping the noncompliant child: A clinician's guide to parent training. New York: Guilford. 
Fox, L., Dunlap, G., \& Powell, D. (2002). Young children with challenging behaviour: Issues and considerations for behaviour support. Journal of Positive Behaviour Support, 4, 208-217.

Goodman, G., Aber, J.L., Berlin, L., \& Brooks-Gunn, J. (1998). The relations between maternal behaviours and urban preschool children's internal working models of attachment security. Infant Mental Health Journal, 19, 378-393.

Green, J., Stanley, C., \& Peters, S. (2007). Disorganized attachment representation and atypical parenting in young school age children with externalizing disorder. Attachment and Human Development, 9, 207-222.

Hoge, R.D., Andrews, D.A., \& Leschied, A.W. (1996). An investigation of risk and protective factors in a sample of youthful offenders. Journal of Child Psychology and Psychiatry, 37, 419-424.

Horner, R.H., Vaughn, B.J., Day, H.M., \& Ard, W.R. (1996). The relationship between setting events and problem behaviour; expanding our understanding of behavioural support. In Koegel, L.K., and Koegel, R.L. et al (Eds.), Positive behavioural support: Including people with difficult behaviour in the community (pp.381-402). Baltimore, M.D.: Paul H. Brookes Publishing Company.

Howes, C., Hamilton, C.E., \& Matheson, C.C. (1994). Children's relationships with peers: Differential associations with aspects of the teacher-child relationship. Child Development, 65, 264-273.

Howes, C., Matheson, C.C., \& Hamilton, C.E. (1994). Maternal, teacher, and child care history correlates of children's relationships with peers. Child Development, 65, 264-273. 
Humber, H., \& Moss, E. (2005). The relationship of preschool and early school age attachment to mother-child interaction. American Journal of Orthopsychiatry, 75, 128-141.

Joseph, G.E., \& Strain, P.S. (2003). Comprehensive evidence-based social-emotional curricula for young children: An analysis of efficacious adoption potential. Topics in Early Childhood Special Education, 23, 65-76.

Katz, L.F., \& Gottman, J.M. (1997). Buffering children from marital conflict and dissolution. Journal of Clinical Child Psychology, 26, 157-171.

Kellam, S.G., Ling, X., Merisca, R., Brown, C.H., \& Ialongo, N. (1998). The effect of the level of aggression in the first grade classroom on the course and malleability of aggressive behavior into middle school. Development and Psychopathology, 10, 165-185.

Kern, L., Choutka, C.M., \& Sokol, N.G. (2002). Assessment-based antecedent interventions used in natural settings to reduce challenging behaviour: An analysis of the literature. Education and Treatment of Children, 25, 113-130.

Kobak, R. (1999). The emotional dynamics of disruptions in attachment relationships: Implications for theory, research, and clinical intervention. New York: Guilford Press.

Kotler, J.C., \& McMahon, R.J. (2002). Differentiating anxious, aggressive, and socially competent preschool children: Validation of the social competence and behaviour evaluation -30 (parent version). Behaviour Research and Therapy, 40, 947-959.

Kupersmidt, J.B. (2000). Prevalence of aggressive behaviour among preschoolers in head start and community care programs. Behavioral Disorders. Special Issue: Assessing and Addressing Problems in Children Enrolled in Head Start, 26, 42-52. 
Ladd, G.W., \& Burgess, K.B.(2001). Do relational risk and protective factors moderate the linkages between childhood aggression and early psychological and school adjustment? Child Development, 72, 1579-1601.

Lewis, M. (1997). Altering fate: Why the past does not predict the future. New York: The Guilford Press.

Linver, M.R., Brooks-Gunn, J., \& Kohen, D.E. (2002). Family processes as pathways from income to young children's development. Developmental Psychology, 38, 719-734.

Luiselli, J.K. (1998). Treatment of self-injurious hand-mouthing in a child with multiple disabilities. Journal of Developmental and Physical Disabilities, 10, 167-174.

Marcus, R.F., \& Betzer, P.D.S. (1996). Attachment and antisocial behaviour in early adolescence. The Journal of Early Adolescence, 16, 229-248.

Martin, G., Pear, J. (1996). Behaviour Modification: What it is and how to do it (5 $5^{\text {th }}$ ed.). Englewood Cliffs, NJ, US: Prentice-Hall Inc.

Mayer, G.R. (2001). Antisocial Behaviour: Its causes and prevention within our schools. Education and Treatment of Children, 24, 414-429.

McCain, M.N, \& Mustard, J.F. (1999). The early years study: Reversing the real brain drain. Toronto: Publications Ontario.

McCarty, C.A., Zimmerman, F.J., Digiuseppe, D.L., \& Christakis, D.A. (2005). Parental emotional support and subsequent internalising and externalising problems among children. Journal of Developmental and Behavioral Paediatrics, 26, 267-275.

McMahon, R.J., \& Forehand, R.L., (2003). Helping the non-compliant child: Family-based treatment for oppositional behaviour. New York: Guilford Press.

Michael, J. (1993). Establishing operations. The Behaviour Analyst, 16, 191-206. 
Michael, J. (2000). Implications and refinements of the establishing operation concept. Journal of Applied Behavior Analysis, 33, 401-410.

O’Connor, E., \& McCartney, K. (2007). Examining teacher-child relationships and achievement as part of an ecological model of development. American Educational Research Journal, 44, 340-369.

Palermo, F., Hanish, L.D., Martin, C.L., Fabes, R.A., \& Reiser, M. (2007). Preschoolers’ academic readiness: What role does the teacher-child relationship play? Early Childhood Research Quarterly, 22, 407-422.

Patterson, G.R. (1982). Coercive family process. Eugene, OR: Castalia.

Peisner-Feinberg, E.S., \& Burchinal, M.R. (1997). Relations between preschool children's child care experiences and concurrent development: The cost, quality, and outcomes study. Merrill-Palmer Quarterly, 43, 451-477.

Peisner-Feinberg, E.S., Burchinal, M.R., Clifford, R.M., Culkin, M.L., Howes, C., Kagan, S.L., and Yazejian, N. (2001). The relation of preschool child care quality to children's cognitive and social developmental trajectories through second grade. Child Development, 72, 1534-1553.

Pianta, R.C. (1999). Why supportive relationships are essential. Enhancing relationships between teachers and children. Washington, D.C.: American Psychological Association.

Pianta, R.C., \& Egeland, B. (1994). Relation between depressive symptoms and stressful life events in a sample of disadvantaged mothers. Journal of Consulting and Clinical Psychology, 62, 1229-1234. 
Pianta, R.C., Steinberg, M.S., \& Rollins, K.B. (1995). The first two years of school: Teacherchild relationships and deflections in children's classroom adjustment. Development and Psychopathology, 7, 295-312.

Pianta, R.C., \& Walsh, D.J. (1998). Applying the construct of resilience in schools: Cautions from a developmental systems perspective. School Psychology Review, 27, 407-417.

Rodewald, H.K. (1979). Stimulus control of behavior. Baltimore: University Park Press.

Rosen, L., O'Leary, S., Joyce, S., Conway, G., \& Pfiffner, L. (1984). The importance of prudent negative consequences for maintaining the appropriate behavior of hyperactive students. Journal of Abnormal Child Psychology, 12, 581-604.

Sawyer, M.G., Arney, F.M., Baghurst, P.A., Clark, J.J., Graetz, B.W., \& Kosky, R.J. (2000). The mental health of young people in Australia. Australia: Mental Health and Special Programs Branch, Commonwealth Department of Health and Aged Care.

Seifer, R., Schiller, M., Sameroff, A.J., Resnick, S., \& Riordan, K. (1996). Attachment, maternal sensitivity, and infant temperament during the first year of life. Developmental Psychology, 32, 12-25.

Shaw, D.S., Keenan, K., Vondra, J.I., Delliquadri, E., \& Giovanelli, J. (1997). Antecedents of preschool children's internalizing problems: A longitudinal study of low-income families. Journal of the American Academy of Child \& Adolescent Psychiatry, 36, 17601767.

Stacks, A.M. (2007). Defensive dysregulation in preschool children's attachment story. School Psychology International, 28, 294-312.

Statistics Canada (2005). The daily. Retreived from www.Statcan.ca 
Stoughton, E.H. (2007). How will I get them to behave?: Pre-service teachers reflect on classroom management. Teaching and Teacher Education, 23, 1024-1037.

Smith, R.G., \& Iwata, B.A. (1997). Antecedent influences on behaviour disorders. Journal of Applied Behaviour Analysis, 30, 343-375.

Turner, H.S., \& Watson, T.S. (1999). Consultant's guide for the use of time-out in the preschool and elementary classroom. Psychology in the Schools, 36, 135-148.

Vandell, D.L. (2004). Early child care: The known and the unknown. Merrill-Palmer Quarterly. Special Issue: The Maturing of the Human Developmetal Sciences: Appraising Past, Present, and Prospective Agenda, 50, 387-414.

Vando, J.,Rhule-Louie, D.M., McMahon, R.J., \& Spieker,S.J.(2008). Examining the link between infant attachment and child conduct problems in grade one. Journal of Child and Family Studies, 17, 615-628.

Wachs, T.D., Gurkas, P., \& Kontos, S. (2004). Predictors of preschool children's compliance behaviour in early childhood classroom settings. Journal of Applied Developmental Psychology, 25, 439-457.

Wahler, R.G., \& Dumas, J. (1984). Changing the observational coding of styles of insular and non-insular mothers: A step towards maintenance of parent training effects. In R.F. Dangel and R.A. Polster (Eds.), Parent Training: Foundations of Research and Practice (pp.379-416). New York: Guilford.

Watson, P.J., \& Workman, E.A. (1981). The non-concurrent multiple baseline acrossindividuals design: An extension of the traditional multiple baseline design. Journal of Behaviour Therapy and Experimental Psychiatry, 12, 257-259. 
Webster-Stratton, C. (2001). The incredible years: Parents, teachers, and children training series. Residential Treatment for Children and Youth. Special Issue: Innovative Mental Health Interventions for Children: Programs That Work, 18, 31-45.

Webster-Stratton, C., \& Hammond, M., (1998). Conduct problems and level of social competence in head start children: Prevalence, pervasiveness, and associated risk factors. Clinical Child and Family Psychology Review, 1, 101-124.

Webster-Stratton, C., Reid, M.J., \& Stoolmiller, M. (2008). Preventing conduct problems and improving school readiness: Evaluation of the incredible years teacher and child training programs in high risk schools. Journal of Child Psychology and Psychiatry, 49, 471-488.

Weiss, L.H. \& Schwartz, J.C. (1996). The relationship between parenting types and older adolescents' personality, academic achievement, adjustment, and substance use. Child Development, 67, 2101-2114.

Werner, E.E. (1999). How children become resilient: Observations and cautions. In Henderson, N., Benard, B., and Sharp-Light, N. (Eds.), Resiliency in Action: Practical Ideas for Overcoming Risks and Building Strengths in Youth, Families, and Communities (pp. 115134). Gorham, ME: Resiliency in Action.

West, J., Denton, K., \& Reaney, L.M. (2001). The kindergarten year: Findings from the early childhood longitudinal study, kindergarten class of 1998-1999 (Publication No. NCES2001-023). Washington, DC: Department of Education, National Center for Education Statistics. 
Wilder, D., Harris, C., Reagan, R., \& Rasey, A. (2007). Functional analysis and treatment of noncompliance by preschool children. Journal of Applied Behaviour Analysis, 40, 173177.

Wilder, D., Saulnier, R., Beavers, G., \& Zonneveld, K. (2008). Contingent access to preferred items versus a guided compliance procedure to increase compliance amongst preschoolers. Education and Treatment of Children, 31, 297-305. 


\author{
Appendix A \\ Informed Consent Packages
}

ONTARIO INSTITUTE FOR STUDIES IN EDUCATION OF THE UNIVERSITY OF TORONTO

\title{
Dear Childcare Supervisor,
}

I am writing you this letter to ask for your participation in a research study that I am conducting as a doctoral student at the University of Toronto. Please read through the information provided and consider your participation in this study. If you are interested in having this study take place within your childcare centre, please contact me at the phone number listed at the end of this letter and we can arrange a time to meet and discuss the research project in greater detail.

\section{What is this study about and how will participants be selected?}

We are interested in carrying out a research study to examine the enhancement of teacher-child rapport with toddler and pre-school aged children. Participants will include one toddler room teacher and one pre-school room teacher, along with several toddler and pre-school age children.

Several childcare centers with toddler and pre-school aged classrooms have been sent an information package about this study. Within those centers, the Centre Supervisor, and the toddler and preschool age classroom teachers have been asked to contact me if they are interested in participating in this study.

Once the Centre Supervisor and the teachers consent to participate in this study, participating teachers will be asked to forward information packages about this study to the parents of all children in their classrooms. Parents will be asked to contact me if they are interested in having their child or children participate in this study. Once informed consent documents have been completed by the parents of the children in each classroom, the study will begin in that classroom.

\section{What will the teachers and children be expected to do during this study?}

This study will take place over the course of five weeks and will begin with the researcher observing the teacher and the children in the classroom. Once these observations are complete, the teachers will be provided with a short professional development session on conducting rapport-building play with children. This short educational session will be scheduled at a time that is convenient for the participating teachers.

The teachers will then be asked to engage in short, one-to-one five-minute play sessions each day with the children participating in this study. These very short daily play sessions will be scheduled at a time of day that is convenient for the participating teachers such as during already scheduled play time. 
The investigator and a research assistant will continue to observe the participating teachers and children in the classroom throughout this research study, and from time to time will observe the teacher-child play sessions. As well, participating teachers will be asked to complete very short checklists indicating the level of participant children's Classroom cooperation over the course of this study.

For one week in the middle of this study, the teacher-child play sessions will not take place, and the teachers will follow the typical classroom routine. As well, during the last week of this study, the teachers will be asked to gradually fade out the play sessions and return to the typical classroom routine.

\section{Will all children participating in this study take part in the play sessions?}

All children participating in this study will take part in the classroom observations, however, not all will participate in the rapport-building play sessions. Children that will most benefit from the play sessions, that is, those children who may be having some difficulty cooperating with their teacher's requests, will be selected to participate in the play sessions.

\section{Why would some children be having difficulty cooperating with teachers' requests and} others not have any difficulty?

It is typical for all toddler and pre-school age children to experience some difficulty cooperating with their teachers' requests. It is also typical that some toddler and preschool age children will be more cooperative to their teachers' requests then others.

\section{What are the potential benefits of this intervention?}

It is anticipated that this intervention will help the children participating in the study because it is positive in nature, and entails one-to-one uninterrupted time for the teacher and child to interact in a warm and fun way.

\section{Is my agreement to participate voluntary and are there any risks to the children participating in this intervention?}

Your participation in this project is completely voluntary and you may change your mind and withdraw your participation at any time.

We do not anticipate any risks to the children with this intervention. Please know that before each play session, each child will be asked if he or she wants to engage in the play session with the teacher. If a child indicates that he or she does not want to play with the teacher, the play session will not take place on that day. As well, if a child indicates that he or she wants to end a play session before the session is scheduled to end, the teacher will immediately end the play session for that day. 


\section{Is the information collected about me, the teachers, and the children confidential?}

Yes. All information collected about the teachers and the children who participate in this study will be kept completely confidential except as required by law. This means, for example, that they may be subject to subpoena as evidence by a court of law. It should also be noted that individuals in Ontario are required by law to report evidence of child abuse or neglect to child welfare authorities. Aside from circumstances such as these, the information we collect will be accessible to me, the research project supervisor, and any students or research assistants who are formally associated with this project.

Please also note that we will publish the results of this study and present them at conferences to share with other professionals. In any papers or presentations related to the findings of this project, we will make sure that the names of teachers, children, and the child care centers are never used.

\section{Are the Teachers' professional skills or the children's academic performance evaluated in any way as a result of this study?}

Please know that there is no aspect of professional evaluation related to the performance of any teacher in this study and that there is no aspect of academic evaluation related to any child in this study. As well, all participant child care centre Supervisors must be willing to agree that they will not put any pressure on teachers to participate in this project, and that they will not use any information stemming from this research project to evaluate the teachers that are participating in the study.

Any information collected during this study will be used only for the purposes of this research project and not for any professional evaluation of the teachers or academic evaluation of the children.

If you have any questions about this study, or would like to discuss this study in greater detail, please feel free to call me at (905) 668-4113 extension 2835 or Dr. Ducharme at (416) 9780936. Please also feel free to contact the Ethics Review Office at the University of Toronto at (416) $946-3273$ if you have any questions about your rights as participants in this research study.

Thank you for considering participating in this project.

Sincerely,

Doctoral Student: Darren Levine, M.Ed., Ontario Institute for Studies in Education of the University of Toronto.

Professor / Supervisor: Dr. Joseph Ducharme, Ph.D., C. Psych., Ontario Institute for Studies in Education of the University of Toronto. 


\section{Childcare Supervisor Consent Form}

I have read the project description, have had the study explained to me, and have had the opportunity to have my questions answered. I agree to participate in this study with the understanding that I may choose not to participate and may withdraw from this study at any time without consequence.

I hereby provide my consent and approval for this study to take place in the toddler and preschool age classrooms at

Signature of Childcare Supervisor

Date 
Dear Childcare Teacher

I am writing you this letter to ask for your participation in a research study that I am conducting as a doctoral student at the University of Toronto. Please read through the information provided and consider your participation in this study. If you are interested in participating in this study, please contact me at the phone number listed at the end of this letter and we can arrange a time to meet and discuss the research project in greater detail.

\section{What is this study about and how will participants be selected?}

We are interested in carrying out a research study to examine the enhancement of teacher-child rapport with toddler and pre-school aged children. Participants will include one toddler room teacher and one pre-school room teacher, along with several toddler and pre-school age children.

Several childcare centers with toddler and pre-school aged classrooms have been sent an information package about this study. Within those centers, the Centre Supervisor, and the toddler and preschool age classroom teachers have been asked to contact me if they are interested in participating in this study.

Once the Centre Supervisor and the teachers consent to participate in this study, participating teachers will be asked to forward information packages about this study to the parents of all children in their classrooms. Parents will be asked to contact me if they are interested in having their child or children participate in this study. Once informed consent documents have been completed by the parents of the children in each classroom, the study will begin in that classroom.

\section{What will the teachers and children be expected to do during this study?}

This study will take place over the course of five weeks and will begin with the researcher observing the teacher and the children in the classroom. Once these observations are complete, the teachers will be provided with a short professional development session on conducting rapport-building play with children. This short educational session will be scheduled at a time that is convenient for the participating teachers.

The teachers will then be asked to engage in short, one-to-one five-minute play sessions each day with the children participating in this study. These very short daily play sessions will be scheduled at a time of day that is convenient for the participating teachers such as during already scheduled play time. 
The investigator and a research assistant will continue to observe the participating teachers and children in the classroom throughout this research study, and from time to time will observe the teacher-child play sessions. As well, participating teachers will be asked to complete very short checklists indicating the level of participant children's classroom cooperation over the course of this study.

For one week in the middle of this study, the teacher-child play sessions will not take place, and the teachers will follow the typical classroom routine. As well, during the last week of this study, the teachers will be asked to gradually fade out the play sessions and return to the typical classroom routine.

\section{Will all children participating in this study take part in the play sessions?}

All children participating in this study will take part in the classroom observations, however, not all will participate in the rapport-building play sessions. Children that will most benefit from the play sessions, that is, those children who may be having some difficulty cooperating with their teacher's requests, will be selected to participate in the play sessions.

\section{Why would some children be having difficulty cooperating with teachers' requests and} others not have any difficulty?

It is typical for all toddler and pre-school age children to experience some difficulty cooperating with their teachers' requests. It is also typical that some toddler and preschool age children will be more cooperative to their teachers' requests then others.

\section{What are the potential benefits of this intervention?}

It is anticipated that this intervention will help the children participating in the study because it is positive in nature, and entails one-to-one uninterrupted time for the teacher and child to interact in a warm and fun way.

\section{Is my agreement to participate voluntary and are there any risks to the children participating in this intervention?}

Your participation in this project is completely voluntary and you may change your mind and withdraw your participation at any time.

we do not anticipate any risks to the children with this intervention. Please know that before each play session, each child will be asked if he or she wants to engage in the play session with the teacher. If a child indicates that he or she does not want to play with the teacher, the play session will not take place on that day. As well, if a child indicates that he or she wants to end a play session before the session is scheduled to end, the teacher will immediately end the play session for that day. 
ONTARIO INSTITUTE FOR STUDIES IN EDUCATION OF THE UNIVERSITY OF TORONTO

\section{Is the information collected about me, the teachers, and the children confidential?}

Yes. All information collected about the teachers and the children who participate in this study will be kept completely confidential except as required by law. This means, for example, that they may be subject to subpoena as evidence by a court of law. It should also be noted that individuals in Ontario are required by law to report evidence of child abuse or neglect to child welfare authorities. Aside from circumstances such as these, the information we collect will be accessible to me, the research project supervisor, and any students or research assistants who are formally associated with this project.

Please also note that we will publish the results of this study and present them at conferences to share with other professionals. In any papers or presentations related to the findings of this project, we will make sure that the names of teachers, children, and the child care centers are never used.

\section{Are the Teachers' professional skills or the children's academic performance evaluated in any way as a result of this study?}

Please know that there is no aspect of professional evaluation related to the performance of any teacher in this study and that there is no aspect of academic evaluation related to any child in this study. As well, all participant child care centre Supervisors must be willing to agree that they will not put any pressure on teachers to participate in this project, and that they will not use any information stemming from this research project to evaluate the teachers that are participating in the study.

Any information collected during this study will be used only for the purposes of this research project and not for any professional evaluation of the teachers or academic evaluation of the children.

If you have any questions about this study, or would like to discuss this study in greater detail, please feel free to call me at (905) 668-4113 extension 2835 or Dr. Ducharme at (416) 9780936. Please also feel free to contact the Ethics Review Office at the University of Toronto at (416) $946-3273$ if you have any questions about your rights as participants in this research study.

Thank you for considering participating in this project.

Sincerely,

Doctoral Student: Darren Levine, M.Ed., Ontario Institute for Studies in Education of the University of Toronto.

Professor / Supervisor: Dr. Joseph Ducharme, Ph.D., C. Psych., Ontario Institute for Studies in Education of the University of Toronto. 


\section{Childcare Teacher Consent Form}

I have read the project description, have had the study explained to me, and have had the opportunity to have my questions answered. I agree to participate in this study with the understanding that I may choose not to participate and may withdraw from this study at any time without consequence.

I hereby provide my consent and approval for this study to take place in my classroom at

Signature of Childcare Teacher

Date 
Dear Parent,

I am writing you this letter to ask for your participation in a research study that I am conducting as a doctoral student at the University of Toronto. Please read through the information provided and consider your child's participation in this study. If you are interested in having your child participate in this study, please contact me at the phone number listed at the end of this letter and we can arrange a time to meet and discuss the research project in greater detail.

\section{What is this study about and how will participants be selected?}

We are interested in carrying out a research study to examine the enhancement of teacher-child rapport with toddler and pre-school aged children. Participants will include one toddler room teacher and one pre-school room teacher, along with several toddler and pre-school age children.

Several childcare centers with toddler and pre-school aged classrooms have been sent an information package about this study. Within those centers, the Centre Supervisor, and the toddler and preschool age classroom teachers have been asked to contact me if they are interested in participating in this study.

Once the Centre Supervisor and the teachers consent to participate in this study, participating teachers will be asked to forward information packages about this study to the parents of all children in their classrooms. Parents will be asked to contact me if they are interested in having their child or children participate in this study. Once informed consent documents have been completed by the parents of the children in each classroom, the study will begin in that classroom.

\section{What will the teachers and children be expected to do during this study?}

This study will take place over the course of five weeks and will begin with the researcher observing the teacher and the children in the classroom. Once these observations are complete, the teachers will be provided with a short professional development session on conducting rapport-building play with children. This short educational session will be scheduled at a time that is convenient for the participating teachers.

The teachers will then be asked to engage in short, one-to-one five-minute play sessions each day with the children participating in this study. These very short daily play sessions will be scheduled at a time of day that is convenient for the participating teachers such as during already scheduled play time. 
The investigator and a research assistant will continue to observe the participating teachers and children in the classroom throughout this research study, and from time to time will observe the teacher-child play sessions. As well, participating teachers will be asked to complete very short checklists indicating the level of participant children's classroom cooperation over the course of this study.

For one week in the middle of this study, the teacher-child play sessions will not take place, and the teachers will follow the typical classroom routine. As well, during the last week of this study, the teachers will be asked to gradually fade out the play sessions and return to the typical classroom routine.

\section{Will all children participating in this study take part in the play sessions?}

All children participating in this study will take part in the classroom observations, however, not all will participate in the rapport-building play sessions. Children that will most benefit from the play sessions, that is, those children who may be having some difficulty cooperating with their teacher's requests, will be selected to participate in the play sessions.

\section{Why would some children be having difficulty cooperating with teachers' requests and} others not have any difficulty?

It is typical for all toddler and pre-school age children to experience some difficulty cooperating with their teachers' requests. It is also typical that some toddler and preschool age children will be more cooperative to their teachers' requests then others.

\section{What are the potential benefits of this intervention?}

It is anticipated that this intervention will help the children participating in the study because it is positive in nature, and entails one-to-one uninterrupted time for the teacher and child to interact in a warm and fun way.

\section{Is my agreement to participate voluntary and are there any risks to the children participating in this intervention?}

Your participation in this project is completely voluntary and you may change your mind and withdraw your participation at any time.

We do not anticipate any risks to the children with this intervention. Please know that before each play session, each child will be asked if he or she wants to engage in the play session with the teacher. If a child indicates that he or she does not want to play with the teacher, the play session will not take place on that day. As well, if a child indicates that he or she wants to end a play session before the session is scheduled to end, the teacher will immediately end the play session for that day. 


\section{Is the information collected about me, the teachers, and the children confidential?}

Yes. All information collected about the teachers and the children who participate in this study will be kept completely confidential except as required by law. This means, for example, that they may be subject to subpoena as evidence by a court of law. It should also be noted that individuals in Ontario are required by law to report evidence of child abuse or neglect to child welfare authorities. Aside from circumstances such as these, the information we collect will be accessible to me, the research project supervisor, and any students or research assistants who are formally associated with this project.

Please also note that we will publish the results of this study and present them at conferences to share with other professionals. In any papers or presentations related to the findings of this project, we will make sure that the names of teachers, children, and the child care centers are never used.

\section{Are the Teachers' professional skills or the children's academic performance evaluated in any way as a result of this study?}

Please know that there is no aspect of professional evaluation related to the performance of any teacher in this study and that there is no aspect of academic evaluation related to any child in this study. As well, all participant child care centre Supervisors must be willing to agree that they will not put any pressure on teachers to participate in this project, and that they will not use any information stemming from this research project to evaluate the teachers that are participating in the study.

Any information collected during this study will be used only for the purposes of this research project and not for any professional evaluation of the teachers or academic evaluation of the children.

If you have any questions about this study, or would like to discuss this study in greater detail, please feel free to call me at (905) 668-4113 extension 2835 or Dr. Ducharme at (416) 9780936. Please also feel free to contact the Ethics Review Office at the University of Toronto at (416) 946-3273 if you have any questions about your rights as participants in this research study.

Thank you for considering participating in this project.

Sincerely,

Doctoral Student: Darren Levine, M.Ed., Ontario Institute for Studies in Education of the University of Toronto.

Professor / Supervisor: Dr. Joseph Ducharme, Ph.D., C. Psych., Ontario Institute for Studies in Education of the University of Toronto. 


\section{Parent Consent Form}

I have read the project description, have had the study explained to me, and have had the opportunity to have my questions answered. I hereby provide my consent and approval for my child, to participate in this study with the understanding that I may choose for my child not to participate and may withdraw my child from this study at any time without consequence.

Signature of Parent (s) 


\section{Appendix B \\ Compliance Probability Checklist}

Child's Name:

Date:

Completed By:

Listed below are a series of requests you may present to a child in a given day. What is the likelihood that the child will comply to this request if the request is stated only once? Please check the appropriate box beside each request.

\begin{tabular}{|l|l|l|l|l|l|l|l|}
\hline & $\begin{array}{l}\text { Almost } \\
\text { Always } \\
76-100 \%\end{array}$ & $\begin{array}{c}\text { Usually } \\
51-75 \%\end{array}$ & $\begin{array}{l}\text { Occasionally } \\
26-50 \%\end{array}$ & $\begin{array}{c}\text { Rarely } \\
0-25 \%\end{array}$ & $\begin{array}{c}\text { Skill Not } \\
\text { Learned }\end{array}$ & $\begin{array}{c}\text { This Request } \\
\text { is important } \\
\text { to me }\end{array}$ & $\begin{array}{c}\text { Group / } \\
\text { Ind. }\end{array}$ \\
\hline $\begin{array}{l}\text { DRESSING } \\
\text { Take off your }\end{array}$ & & & & & & & \\
\hline Hang up your & & & & & & & \\
\hline Get your & & & & & & & \\
\hline Other: & & & & & & & \\
\hline HYGIENE & & & & & & & \\
\hline $\begin{array}{l}\text { Wash your } \\
\text { Hands }\end{array}$ & & & & & & & \\
\hline Turn on the tap & & & & & & & \\
\hline Turn off the \\
Tap
\end{tabular}




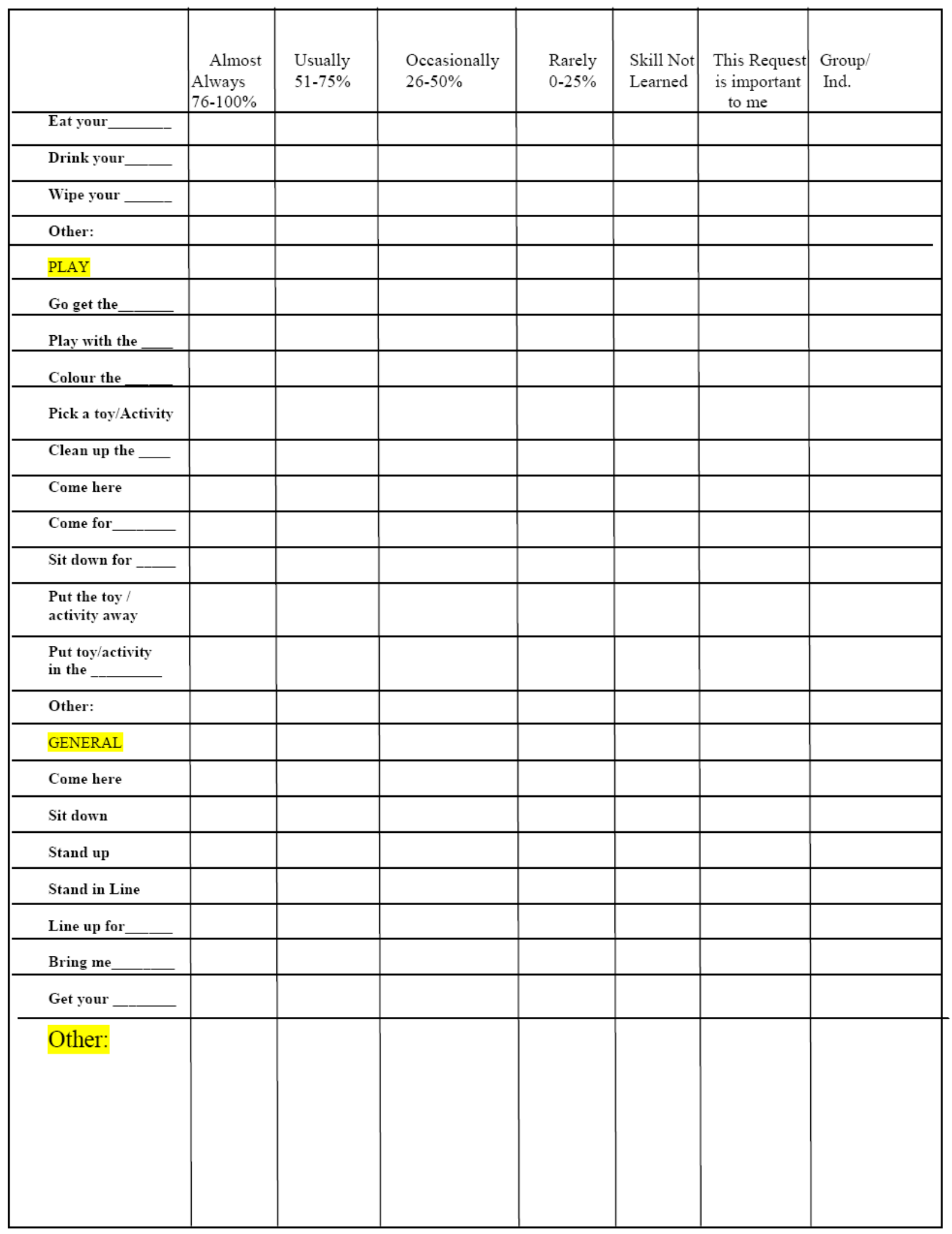

Adapted from Ducharme \& DiAdamo (2005) 


\section{Appendix C \\ Child Compliance Data Collection Form}

Date

Child's Name
Completed by

Time

Compliance: Initiation of the appropriate motor response to the teacher's request within 10 seconds of the request, and completion of the motor response within 40 seconds.

\begin{tabular}{|c|c|c|}
\hline $\begin{array}{l}\text { Request } \\
1 .\end{array}$ & $\frac{\text { Response }}{(\text { check or } \mathrm{X})}$ & $\begin{array}{l}\text { Group Or Individual Request } \\
\text { Individual }\end{array}$ \\
\hline 2. & & Individual \\
\hline 3. & & Group \\
\hline 4. & & Individual \\
\hline 5. & & Individual \\
\hline & 15 & \\
\hline
\end{tabular}


Appendix D

Researcher Child Compliance and Procedural Integrity Data Collection Form

Date

Child's Name

Completed by

Time

Session Phase: BL Play 1 Withdrawal Play 2 Play Fading

Compliance: Initiation of the appropriate motor response to the teacher's request within 10 seconds of the request, and completion of the motor response within 40 seconds.

\begin{tabular}{|c|c|c|c|}
\hline $\begin{array}{l}\text { Request } \\
1 .\end{array}$ & $\begin{array}{l}\text { Child } \\
\text { Compliance } \\
\text { (check or } \mathrm{x})\end{array}$ & \begin{tabular}{|c|} 
Group or \\
Individual Request
\end{tabular} & $\begin{array}{l}\text { Request Delivered } \\
\text { Correctly } \\
\text { (check or x) }\end{array}$ \\
\hline 2. & & & \\
\hline 3. & & & \\
\hline 4 & & & \\
\hline 5. & & & \\
\hline & 15 & & 15 \\
\hline
\end{tabular}

\begin{tabular}{|l|l|}
\hline Positive Teacher-Child & Number of Occurrences \\
Interactions & \\
e.g.,- warm responsiveness & \\
- praise & \\
- sensitivity & \\
- playfulness & \\
- positive attention/interest & \\
\hline
\end{tabular}

\section{Teacher-Child Play Session}

Conducted: __ (check or $\mathrm{x}$ )

Child Assent to Participate: ___ (check or x)

Start Time:__ End Time:

Administered Correctly: ___ (check or x) 